\title{
Computerized Cognitive Training in Healthy Older Adults: Baseline Cognitive Level and Subjective Cognitive Concerns Predict Training Outcome
}

\author{
Elke Kalbe1 $^{*}$, Christophe Bintener ${ }^{2 *}$, Anja Ophey', Christian Reuter ${ }^{3}$, Stefan Göbel ${ }^{3}$, \\ Silvie Klöters ${ }^{4}$, Gisela Baller ${ }^{2}$, Josef Kessler ${ }^{4}$ \\ ${ }^{1}$ Department of Medical Psychology/Neuropsychology and Gender Studies \& Center for Neuropsychological Diagnostics and \\ Intervention (CeNDI), University Hospital Cologne, Cologne, Germany \\ ${ }^{2}$ Institute of Gerontology, Department of Psychological Gerontology, University of Vechta, Vechta, Germany \\ ${ }^{3}$ Multimedia Communications Lab-KOM, Technische Universität Darmstadt, Darmstadt, Germany \\ ${ }^{4}$ Department of Neurology, University Hospital Cologne, Cologne, Germany \\ Email: elke.kalbe@uk-koeln.de
}

How to cite this paper: Kalbe, E., Bintener, C., Ophey, A., Reuter, C., Göbel, S., Klöters, S., Baller, G. and Kessler, J. (2018) Computerized Cognitive Training in Healthy Older Adults: Baseline Cognitive Level and Subjective Cognitive Concerns Predict Training Outcome. Health, 10, 20-55. https://doi.org/10.4236/health.2018.101003

Received: August 30, 2017

Accepted: January 1, 2018

Published: January 4, 2018

Copyright (๑ 2018 by authors and Scientific Research Publishing Inc. This work is licensed under the Creative Commons Attribution International License (CC BY 4.0).

http://creativecommons.org/licenses/by/4.0/ c) $\underset{\mathrm{EY}}{\mathrm{i}}$ Open Access

\begin{abstract}
Computerized cognitive training (CCT) can improve cognition in older adults. However, specific programs for this target group have rarely been developed, and predictors of training success are largely unclear. In a randomized controlled pilot trial, we examined effects of a six-week CCT, tailored to the cognitive profile of healthy older adults (EG, $n=21$ ) as compared to a nonspecific CCT (CG, $n=18$ ) matched in frequency and intensity. No interaction effects between Group and Time were found. However, within-group analysis showed significant gains in verbal and non-verbal memory, executive and visuospatial functions and subjective cognitive concerns (SCC) in the EG, while the CG only benefitted in non-verbal memory and set-shifting. Low cognitive performance and lower SCC at baseline were the most consistent predictors of cognitive gains in the EG. Thus, CCTs specifically tailored to older adults seem advantageous compared to non-specific CCT. Further, we conclude that SCC may be related to reduced cognitive plasticity.
\end{abstract}

\section{Keywords}

Computerized Cognitive Training, Older Adults, Subjective Cognitive

Decline, Psychoeducation, Predictors 


\section{Introduction}

Recently, cognitive interventions to enhance cognitive functions and attenuate cognitive decline in healthy elderly individuals have attracted increasing scientific attention. There is robust evidence that the aging brain is amenable to neuronal and cognitive plasticity [1] [2] [3] and has the potential to enhance cognition and possibly everyday functioning through cognitive training (CT; [4] [5] [6] [7] [8]). However, more research with standardized training protocols and outcome measures is necessary to allow conclusions about the optimal type and dose of cognitive interventions [4].

Computerized cognitive trainings (CCT) have the advantage that they can be administered at home and are usually not cost-intensive. A systematic review of [9] reported that studies with CCTs found benefits in global cognitive performance, reaction time, processing speed, working memory, executive function, attention, memory, and visual spatial ability in older adults. Effect sizes differed according to the type of computerized program used-classic CT tasks, neuropsychological software, and video games. However, in a recent systematic review, which classified studies on CCT in healthy older adults regarding their evidence level, the two studies providing Level III only reported memory improvement with medium to large effects and one of these studies additionally found benefits in processing speed with a large effect size [10]. Importantly, the type of CT tasks seems to play an important role [10]. Reference [9] concluded that classic CT tasks provided the best results (with the exception of gains in reaction time for which video games were most effective) and that effects of these tasks are most comparable benefits to more traditional CT approaches. Finally, a systematic review and meta-analysis of [11] also emphasized that benefits of CCT in healthy older adults are largely determined by design aspects of the training. Their findings indicate that supervised training is more effective than home-based CCTs, and that an intensity of 30 minutes per session with not more than three sessions per week is most favorable [11].

Remarkably, CCTs specifically tailored to the typical cognitive profile of healthy elderly individuals, which is characterized by decline in episodic memory, executive functions, attention and processing speed, but sometimes also visuospatial dysfunctions [12] [13] [14], are rare. Furthermore, psychoeducational elements e.g. with topics related to healthy cognitive aging including risk and protective factors, mechanisms of cognitive functions, or cognitive strategies are part of some cognitive group trainings which were developed for elderly people with or without cognitive dysfunctions [15] [16] [17] [18], but are usually not implemented in digital trainings. However, standardized CCT programs tailored for elderly people could be especially useful, as they would constitute a form of "guided" training [11] for this group. Thus, whether CCTs that are specifically tailored to the profile of healthy elderly and that include psychoeducational elements, e.g. delivered with videos, are more effective than untailored CCTs, is a worthy topic which needs research. 
Predicting training response may be helpful to define which individuals will profit most from which type of CT. In studies examining effects of CT and combined interventions (e.g. CT with physical exercise) in healthy elderly people, cognitive baseline performance [17] [19] [20] [21] and also genetic and neurobiological factors [17] [22] [23] have been identified as possible predictors for training success, although data are inconsistent, as for example both low [17] [20] [21] and high [19] cognitive baseline performance have been associated with training gains. Depressive symptoms seem to be a negative predictor for training success; for example [24] found, in healthy old adults, depressive symptoms are associated with a reduced ability to utilize cognitive resources [see also [25]] and thus, with a reduced ability to profit from memory training. Additionally, a more recent study of [26] identified depressive symptoms as a moderating variable between (low) cognitive scores and cognitive gains induced by a cognitive stimulation program in elderly with dementia. The negative influence of depression on training success may be due to reduced motivation and alertness [27] [28], concentration problems, as well as impaired self-confidence.

Indications that computer familiarity does not seem to be predictive for success of computer-based memory training [29] suggest that CCT has the potential to be a practical and viable method for delivering interventions, even for elderly people without digital familiarity. In patients with cognitive impairment (mild cognitive impairment or dementia), the outcomes of cognitive interventions are related not only to baseline cognitive performance [26] [30] baseline functional abilities and behavioural symptoms [31], but also age [32] [33], sex [17] [32] [34], education [35], and again genetic factors [31] have been related to outcomes of cognitive interventions, although findings rely on only few studies with partly inconsistent results. Remarkably, based on the literature, further predictors of CT success exist, but are so far under investigated; these include self-efficacy [36], motivation [37] [38], and subjective cognitive concerns, the latter of which constitute a risk factor for later dementia [39] [40]. Taken together, data suggest that several factors may predict CCT's outcome, but further research is necessary.

On the basis of the noted considerations, the aims of this pilot study were (i) to investigate the effects of an adaptive CCT program specifically developed for aging people including psycho educational elements presented in videos on topics related to healthy cognitive aging, mechanisms of cognitive functions, as well as cognitive strategies, and (ii) to define predictors of intervention outcomes. For this purpose, we conducted a randomized controlled, single blind study, in which healthy elderly individuals received either a structured six week CCT specifically developed for this target group, or a less structured control CCT not tailored to this group, but comparable in frequency and intensity. Planning and reporting followed the recommendations of the CONSORT Statement for RCT [41] [42] [43]-except for the fact that blinding of neuropsychological assessment pre- and post intervention could not be achieved and only post-hoc power 
calculation was performed. We hypothesized that the tailored CCT program would induce more positive effects on cognitive outcomes compared to a control intervention. Furthermore, we expected that sociodemographic and cognitive performance at baseline as well as self-efficacy, motivation, depression score, and subjective cognitive concerns would predict the intervention's outcome. Furthermore, in a more explorative way, we also examined whether technology commitment predicted training outcome.

\section{Materials and Method}

The present study was conducted in compliance with the World Medical Association Declaration of Helsinki [44]. The study was approved by the Ethics Committee of the University of Vechta, Germany and is registered at the WHO ICTRP (ID: DRKS00010096). All participants gave written informed consent before the first neuropsychological assessment.

\subsection{Participants}

Healthy independent home dwelling participants aged between 55 and 100 years were recruited by the two study German centers Cologne and Vechta in the cities Cologne and Düsseldorf as well as Vechta, Bremen and Osnabrück, respectively. Individuals were recruited with flyers distributed via local pharmacies and through presentations at a Senior Service Center in Bremen. Participants did not receive monetary compensation. At first, individuals interested in the study were given standardized information either by telephone or, for those attending the presentations, on site. This information included the aims and the course of the study, inclusion and exclusion criteria, as well as a short description of the neuropsychological assessment. In case people were interested in participating in the study, personal information was collected and individuals were contacted later for the study.

The inclusion criteria were: male and female individuals aged 55 or older, native German language or very good German language, normal or sufficiently corrected vision and hearing ability, motor capacities that ensured an unimpaired work on a computer and written informed consent to participate in the study. Exclusion criteria were: psychiatric or neurological disorder, cognitive impairment operationalized by the Montreal Cognitive Assessment (MoCA; cut-off score < 26 points; [45]), mild or clinically relevant depressive symptoms, operationalized by the German version of the Beck Depression Inventory 2 (BDI-II; cut-off score > 12; [46]), current drug abuse, and life-threatening illness.

\subsection{Study Design}

The study was designed as a multicenter, single-blind RCT including a digital cognitive experimental and a digital cognitive control training intervention, which are described below. Participants were allotted randomly to one of these two interventions. The allocation of participants to one of the two interven- 
tions was conducted separately for each of the two study centers in Cologne and Vechta by using a computer-based Research Randomizer program (http://www.randomizer.org). For this purpose, random codes consisting of six letters and two digits were produced by a staff member and consecutively assigned to each participant. Furthermore, a random list for the allocation to the interventions was produced by a staff member not involved in the study and linked to the participants' codes. However, if an individual failed the screening or discontinued training, the next recruited person was assigned to the intervention type which was originally planned for the person that had dropped out. By these means, a balanced number of participants was allocated to both types of interventions.

\subsection{Procedure}

The screening and, in case of eligibility of the participant, the administration of the neuropsychological test battery, as well as the introduction to the training occurred within one visit-either at the participants' home or at one of the study centers. It was performed by a staff member trained in neuropsychological testing. After written consent was obtained, the inclusion and exclusion criteria were checked via interview and MoCA cognitive screening. Afterwards, the neuropsychological test battery was conducted. After that, each participant received an introduction to the operation of the interventional program he or she was allocated to. If necessary, participants also received an introduction to the digital device of the intervention (computer or tablet, please see description of interventions below). Additionally, participants received a standardized study folder, containing contact details in the case of technical problems or other questions, the course of each training lesson including information on every module of this lesson, a formula in which a "school grade" could be given for each module, and finally, space for comments on each session. Furthermore, information on how to adapt the degree of difficulty of the exercises to participants' personal performance level was provided.

The adaptation to the individual difficulty level was possible in all exercises of the experimental training, but only in two exercises of the control training. Participants were asked to start the training program within seven days after screening and pretest. During the first week of training, participants were contacted by telephone in order to assess possible problems with the device or the program. After three weeks (which represents $50 \%$ of the duration of intervention), a home visit was made to check whether the progress of the training and the training itself was running well. Regular telephone consultation hours were offered three times per week for the complete duration of the intervention period.

Neuropsychological assessment took place within one week prior and post intervention. One exception was a posttest 19 days after the end of the experimental training, in which earlier assessment was not possible due to organizational 
reasons. If available, counterbalanced parallel forms of the tests were used to reduce retest effects.

\subsection{Experimental and Control Intervention}

Both the experimental and the control training were comparable with regard to frequency and intensity in order to warrant comparability. Both trainings consisted of eighteen lessons, with an average training period of 40 to 45 minutes each. Training sessions were performed three times per week over a period of six weeks. Every session contained two exercises (one 20 and one 10 minutes), a video (10 - 15 minutes), and an "advice of the day". An overview on the structure of both interventions with examples of the exercises is given in Table S1 and Figures S1-S10 of the Supplementary Material.

\subsubsection{Experimental Intervention}

The "NeuroVitAALis" Software which has been designed on the basis of the paper and pencil multidomain cognitive group training program "NEUROvitalis" (for a detailed description, see [18] [47]) and was prototypically implemented by the Serious Games group at Technische Universität Darmstadt, using the authoring environment StoryTec (http://www.storytec.de; [48] [49]). The "NeuroVitAALis" Software is a neuropsychological software application for tablet computers targeting the stabilization and amelioration of age-sensitive functions on the basis of brain plasticity.

The first exercise (20 minutes) of each session targets either memory or executive functions. The second exercise (10 minutes) could be chosen by the user and either trained spatial cognition, attention, language, or, if not already practiced during the session, either memory or executive function. All exercises had different levels of difficulty (with three to twenty-four levels). Each session also contained a psychoeducational video (10 - 15 minutes) on topics related to healthy cognitive aging or to cognitive functions and cognitive strategies. Finally, an "advice of the day" was given which aimed at the stimulation of cognitive, mnestic, and social activities as well as structuring the day. One example would be the following: "Do you plan to buy groceries today? Try to memorize your shopping list and do your groceries without using it. Check the list after you have gathered all products in order to review that you did not forget something." The tasks were designed to autonomously adapt to the performance level of the user. However, as the program was still in a pilot phase, the automatic adjustment of difficulty levels was not implemented during the study period yet. In order to approximate comparability to a fully structured automated program, the study protocol included concrete instructions on how to adapt the degree of difficulty of the exercises to participants' personal performance level.

After thirteen lessons, two individuals reported that the exercise for the training of executive functions had an undemanding degree of difficulty on its highest level. After consultation with the research group, a modification of the study protocol was administered in these cases, and the exercise was replaced by the 
exercise for spatial cognition on level ten, which is highly demanding and also requires executive functions in its operation.

\subsubsection{Control Intervention}

The control training was conducted on computers. Exercises were taken from the German dyslexia software "Tintenklex" (http://www.legasthenie-software.de) and did not specifically aim at the amelioration of age-sensitive functions. Ten different tasks were chosen training reading abilities, orthography, perception, concentration, visual-spatial perception as well as visual-motor skills. In each session, two tasks defined in the study protocol were trained 20 and 10 minutes, respectively. Videos of 10 - 15 minutes that do not belong to the software were chosen from freely available sources from the internet and included topics like doing sports and exercise, nutrition, relaxation, stress and sleep. Participants watched one video per training lesson. The "advices of the day" (one per training lesson) focused on healthy aging and achievement of well-being in a more general way than in the experimental intervention. They did not focus on cognition.

\subsection{Neuropsychological Assessment}

\subsubsection{Outcome Measures}

Verbal memory was assessed with the German verbal learning and memory test "Verbaler Lern- und Merkfähigkeitstest" (VLMT; [50]). VLMT 1-5 as the sum of words recalled in the five presentation runs was used as an indicator of intermediate verbal memory, and VLMT 7 as the amount of words recalled in the delayed condition and an indicator of verbal long term memory. For the assessment of figural memory, the Wechsler Memory Scale (German version) subtest Visual Reproduction (WMS VR; [51]) with a direct and delayed recall condition was used. The "Brief Test of Attention" (BTA; [52]) was performed to assess attention. As measures of speed of processing and set shifting as an executive function, the "Trail Making Tests A and B" (TMT A \& B; [53] [54]) was performed. Executive functions were also operationalized with verbal letter and alternating semantic fluency tasks using the "Regensburger Wortflüssigkeits Test" (RWT; [55]). As recommended in the manual ([55], p.15), two different letter fluency tasks (P and $\mathrm{M})$ and two alternating semantic fluency tasks (SportsFruits and Clothing-Flowers) were used for the two points of measurement at pre- and posttest. Furthermore, planning was assessed with the Key Search Task a subtest of the "Behavioural Assessment of Dysexecutive Syndrome" (BADS; [56]) test battery. Finally, for the assessment of visuospatial functioning, the subtest nine (visuospatial imagination) from the "Leistungsprüfsystem für 50 90 jährige" (LPS 50+; [57]) was used.

To assess Subjective Cognitive Concerns (SCC) a modified and extended version of the Subjective Memory Impairement Questionnaie (SMI-Q) proposed by [40] was used. The extended version of the SMI-Q contains "yes or no" questions concerning subjective cognitive impairment in five cognitive functions (memory; attention; language; executive functions; and visual-spatial skills), e.g. 
“Do you feel like your memory is becoming worse?”. Furthermore, for each subjectively impaired cognitive domain, worries concerning this experienced worsening were assessed, i.e. "If yes, does that worry you?" with four answer options "No", "Sometimes", "Yes, that worries me", "I don't know". Total scores for subjectively impaired cognitive domains (0 - 5 points) and worries (0 - 10 points) were created.

\subsubsection{Further Scales Used for the Predictor Analysis of Training Success} Further variables used for the predictor analysis of training success were technology commitment (consisting of technology acceptance, technology competence and technology control) as assessed using the technology commitment scale [58] as well as self-efficacy as measured using the SWE-Scale [59]. Individual motivation was assessed by an average grade calculated by school rates ( 1 to 6 comparable to the A to F system) the participants gave before ("How motivated are you to do the training today?") and after ("How did you like the training today?") each session. Alternatively, in individuals who failed to fill in grades for all sessions, a single average grade for the intervention was obtained retrospectively via telephone interviews. BDI-II depression scores obtained at screening were also included in the analyses.

\subsection{Statistical Analyses}

Statistical analyses were performed using IBM SPSS Statistics 23 for Windows (2015). Post-hoc power analysis was performed using the software $G{ }^{*}$ Power 3.1.7 [60]. Normal distributions were tested using the Kolmogorov-Smirnov test. In case of normally distributed measures, parametric analysis was performed. Otherwise, non-parametric tests were used.

Baseline data of experimental and control group were compared between groups, using t-tests for independent samples to compare the age, years of education (including both school and professional education), cognitive state (MoCA), depression score (BDI-II), technology commitment, self-efficacy (SWE) and motivation assessed via an average grade, and chi-square test for the comparison of sex distribution. As Kolmogorov-Smirnov test for normality indicated that neuropsychological data could not be assumed to be normally distributed $(0.086 \geq \mathrm{D} \leq 0.275$ with pre- and/or posttest scores at $\mathrm{p}<0.05$ in $69.23 \%$ of the tests), non-parametric analyses were performed. To quantify the gains achieved within the experimental and control training, we calculated reliable change indices (RCIs; [61]) if valid information on the reliability of the test was available in the literature. In other cases, percentage change scores were calculated. RCIs were preferred as they consider the reliability of the measure. Mann-Whitney-U tests were used to compare the gains between experimental and control group. As a second analysis, changes in neuropsychological measures from pre- to posttest within the intervention groups were analyzed with Wilcoxon signed-rank tests. For all comparisons, the significance level was set at $\alpha=0.05$.

Predictors of training success within the EG were estimated using backwards 
multiple regressions to ensure achievement of best model fit while taking into account each relevant predictor. The significance level was set at $\alpha=0.10$. Based on the current literature outlined above, the following predictors were integrated in the regression models: baseline level of the cognitive tests, depression score, motivation, SCC, technology commitment, age, years of education, sex, and self-efficacy. For the analyses, the SCC SMI-Q extended version total score of subjectively impaired cognitive domains ( 0 - 5 points) was used, as only the perceived number of subjectively impaired cognitive domains has a predictive value, but not the intensity of worries about the perceived worsening. The assumptions for multiple regression were checked according to the suggestions of [62].

\section{Results}

\subsection{Process of the Study and Feasibility}

Data assessment took place between March 2015 and October 2015. $N=54$ persons were assessed for eligibility and randomized, of which a total of $N=49$ engaged in the training conditions EG $(n=28)$ and CG $(n=21)$. During the study, $n=10(20.4 \%)$ persons dropped out due to technical issues with the software and/or hardware issues and, consequently, deviations from the training protocol (EG: $n=3$; CG: $n=1$ ), discontinuation of the training (EG: $n=4$; CG: $n=1$ ), and non-compliance with the training protocol (CG: $n=1$ ). Thus, a total of $N=$ 39 datasets (EG: $n=21$; CG: $n=18$ ) were included for statistical analysis. The flow of participants during the study including information for the flow of participants per study center is presented in Figure 1.

\subsection{Sociodemographic and Neuropsychological Characteristics of the Study Samples}

Baseline data, including sociodemographic characteristics, the overall cognitive state as assessed with the MoCA, BDI-II score, technology commitment, SWE self-efficacy, as well as motivation during the intervention assessed via an average grade, are presented in Table 1. Participants of the EG and CG were comparable with regard to age $[t(37)=-1.120, p=0.270]$, years of education $[t(37)=$ $1.508, p=0.140]$, sex $\left[\chi^{2}=0.774, p=0.379\right]$ and overall cognitive state [MoCA; $t(37)=-0.866, p=0.392]$. Additionally EG and CG did not differ in BDI-II scores $[t(37)=-0.374, p=0.710]$, technology commitment $[t(37)=0.436, p=$ $0.665]$, self-efficacy $[t(37)=0.221, p=0.826]$ and motivation during the intervention $[t(37)=1.640, p=0.109]$. There were no missing data points for the neuropsychological tests.

\subsection{Analysis of Effectiveness}

\subsubsection{Pre- to Posttest Change Comparisons between Groups}

For the analysis of pre- and posttest group comparisons $(N=39,2$-tailed $\alpha=$ 0.05 ) the power to detect small effects (Cohen's $d \geq 0.2$ ) was $9.2 \%$, the power to detect moderate effects (Cohen's $d \geq 0.5$ ) was $32.3 \%$ and the power to detect 


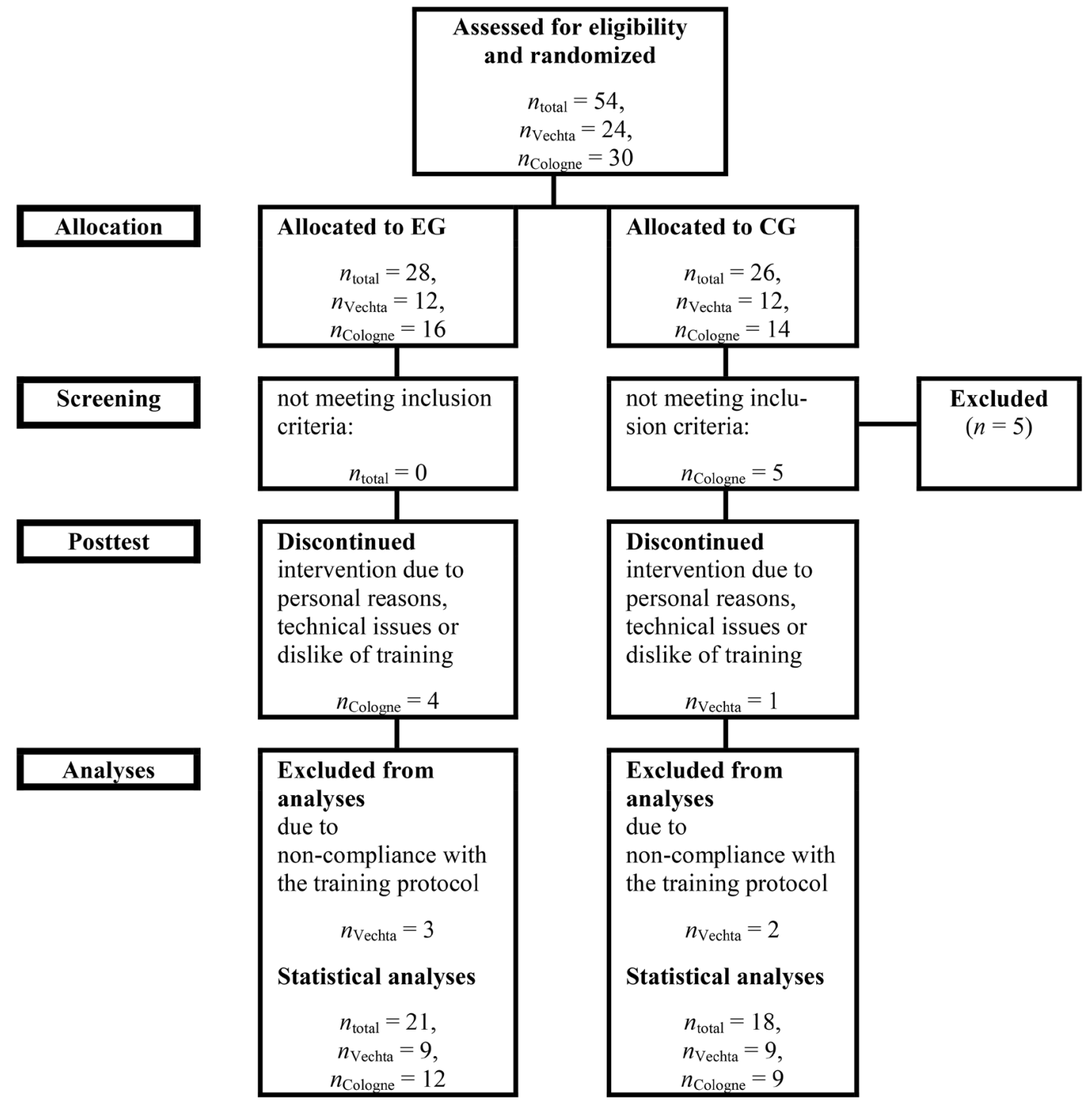

Figure 1. Flow of participants trough the study. EG, Experimental condition; CG, Control condition.

Table 1. Baseline characteristics of the study sample.

\begin{tabular}{|c|c|c|c|c|c|}
\hline & \multicolumn{3}{|c|}{ Experimental Condition $n=21$} & \multicolumn{2}{|c|}{ Control Condition $n=18$} \\
\hline & Max. & $M$ & $(S D)$ & $M$ & $(S D)$ \\
\hline Age & - & 66.14 & $(6.17)$ & 68.50 & $(6.97)$ \\
\hline Education & - & 16 & $(2.57)$ & 14.72 & $(2.72)$ \\
\hline Sex & - & 우 $=15$ & $\hat{o}=6$ & 우 $=15$ & $\hat{o}=3$ \\
\hline Cognitive Screening: MoCA & 30 & 27.43 & $(1.17)$ & 27.78 & $(1.35)$ \\
\hline Depression: BDI-II & 63 & 4.90 & $(3.89)$ & 5.33 & $(3.14)$ \\
\hline Technology commitment & 5 & 3.44 & $(0.60)$ & 3.36 & $(0.60)$ \\
\hline Self-efficacy: SWE & 40 & 30.57 & $(4.04)$ & 30.28 & $(4.24)$ \\
\hline Motivation & 6 & 2.23 & $(0.62)$ & 1.92 & $(0.53)$ \\
\hline
\end{tabular}

Note. BDI-II = Beck Depression Inventory. MoCA = Montreal Cognitive Assessment. SWE = Self-Efficacy Expectation . 
strong effects (Cohen's $d \geq 0.8$ ) was $67.1 \%$. Outcome data for pre- and posttest are presented in Table 2; RCIs and change scores of outcome variables are shown in Table 3. The analysis of differences, based on RCIs or percentage change scores, between groups did not reveal significant results in any outcome

Table 2. Pre-/Post test comparison of test performance in both intervention groups.

\begin{tabular}{|c|c|c|c|c|c|c|c|}
\hline & \multirow[b]{3}{*}{ Max. } & \multicolumn{3}{|c|}{ Experimental Condition $(n=21)$} & \multicolumn{3}{|c|}{ Control Condition $(n=18)$} \\
\hline & & \multicolumn{2}{|c|}{$\begin{array}{c}M(S D) \\
M d(\text { Range })\end{array}$} & \multirow[t]{2}{*}{$T^{b}$} & \multicolumn{2}{|c|}{$\begin{array}{c}M(S D) \\
M d(\text { Range })\end{array}$} & \multirow[t]{2}{*}{$T^{b}$} \\
\hline & & Pretest & Posttest & & Pretest & Posttest & \\
\hline \multicolumn{8}{|c|}{ COGNITIVE STATUS } \\
\hline $\mathrm{MoCA}$ & 30 & $\begin{array}{c}27.29(1.27) \\
27(4)\end{array}$ & $\begin{array}{c}27.72(1.79) \\
28(6)\end{array}$ & 88.5 & $\begin{array}{c}27.50(1.54) \\
28(4)\end{array}$ & $\begin{array}{c}27.28(2.24) \\
\quad 28(7)\end{array}$ & 42 \\
\hline \multicolumn{8}{|c|}{ MEMORY } \\
\hline \multicolumn{8}{|c|}{ Verbal Memory } \\
\hline $\begin{array}{l}\text { Immediate recall } \\
\text { VLMT } 1 \text { - } 5\end{array}$ & 75 & $\begin{array}{c}49.57(6.06) \\
48(23)\end{array}$ & $\begin{array}{c}54.29(7.35) \\
54(23)\end{array}$ & $163.5^{* *}$ & $\begin{array}{c}53.17(10.88) \\
56.5(32)\end{array}$ & $\begin{array}{c}55.94(9.59) \\
57.5(32)\end{array}$ & 121 \\
\hline $\begin{array}{l}\text { Delayed recall } \\
\text { VLMT } 7\end{array}$ & 15 & $\begin{array}{l}10.24(2.12) \\
11(9)\end{array}$ & $\begin{array}{l}11.90(2.17) \\
12(9)\end{array}$ & $152.5^{\star *}$ & $\begin{array}{c}10.94(3.82) \\
12.5(12)\end{array}$ & $\begin{array}{l}12.11(2.65) \\
12(10)\end{array}$ & 91.5 \\
\hline \multicolumn{8}{|c|}{ Figural Memory } \\
\hline $\begin{array}{l}\text { Direct recall } \\
\text { WMS VR }\end{array}$ & 42 & $\begin{array}{c}34.43(5.64) \\
34(24)\end{array}$ & $\begin{array}{c}37.33(5.58) \\
39(22)\end{array}$ & $162^{\star *}$ & $\begin{array}{c}35.5(4.96) \\
34.5(18)\end{array}$ & $\begin{array}{c}37.28(3.79) \\
37.5(13)\end{array}$ & 71 \\
\hline $\begin{array}{l}\text { Delayed Recall } \\
\text { WMS VR }\end{array}$ & 42 & $\begin{array}{c}27.05(7.60) \\
28(28)\end{array}$ & $\begin{array}{c}31.90(8.66) \\
34(35)\end{array}$ & $186^{* *}$ & $\begin{array}{c}28.33(7.81) \\
28(27)\end{array}$ & $\begin{array}{c}32.33(8.88) \\
34(26)\end{array}$ & $118.5^{\star *}$ \\
\hline \multicolumn{8}{|c|}{ ATTENTION } \\
\hline BTA & 20 & $\begin{array}{l}17.10(2.21) \\
18(8)\end{array}$ & $\begin{array}{c}17.95(1.75) \\
18(8)\end{array}$ & 100.5 & $\begin{array}{c}16.94(2.04) \\
17(7)\end{array}$ & $\begin{array}{c}17.44(1.85) \\
18(7)\end{array}$ & 77 \\
\hline \multicolumn{8}{|c|}{ Processing Speed } \\
\hline $\mathrm{TMT} \mathrm{A}^{\mathrm{a}}$ & - & $\begin{array}{c}38.32(22.08) \\
31.3(103.2)\end{array}$ & $\begin{array}{c}34.24(11.86) \\
31(47.57)\end{array}$ & 85.5 & $\begin{array}{c}36.95(9.12) \\
35(42.9)\end{array}$ & $\begin{array}{c}34.68(8.54) \\
34.91(31.24)\end{array}$ & 63.5 \\
\hline \multicolumn{8}{|c|}{ EXECUTIVE FUNCTIONS } \\
\hline Key Search & 16 & $\begin{array}{l}11.90(2.93) \\
11(9)\end{array}$ & $\begin{array}{c}12.62(3.28) \\
13(12)\end{array}$ & 74 & $\begin{array}{c}13.72(2.52) \\
14.5(7)\end{array}$ & $\begin{array}{c}12.78(3.06) \\
12.5(9)\end{array}$ & 16.5 \\
\hline \multicolumn{8}{|c|}{ Verbal Fluency } \\
\hline Verbal letter & - & $\begin{array}{c}19.57(5.92) \\
20(23)\end{array}$ & $\begin{array}{c}19.14(6.19) \\
19(28)\end{array}$ & 64 & $\begin{array}{c}21.78(6.92) \\
20(26)\end{array}$ & $\begin{array}{c}21.50(7.45) \\
21.5(26)\end{array}$ & 64.5 \\
\hline Semantic-alternating & & $\begin{array}{l}23.67(4.96) \\
24(19)\end{array}$ & $\begin{array}{l}22.43(4.49) \\
22(17)\end{array}$ & 74 & $\begin{array}{c}25.28(6.31) \\
23.5(28)\end{array}$ & $\begin{array}{l}22.22(4.49) \\
22.5(15)\end{array}$ & $37.5^{\star}$ \\
\hline TMT B $^{\mathrm{a}}$ & - & $\begin{array}{c}79.96(31.19) \\
73(115.15)\end{array}$ & $\begin{array}{c}\text { Set Shiftin } \\
71.52(24.72) \\
68(76.36)\end{array}$ & $52^{*}$ & $\begin{array}{l}78.10(22.51) \\
72.4(78.4)\end{array}$ & $\begin{array}{l}68.29(24.72) \\
65.28(76.61)\end{array}$ & $28^{*}$ \\
\hline \multicolumn{8}{|c|}{ Visual Spatial Abilities } \\
\hline LPS $50+$ & 40 & $\begin{array}{c}19.48(4.96) \\
20(18)\end{array}$ & $\begin{array}{c}21.43(4.52) \\
21(16)\end{array}$ & $186.5^{\star}$ & $\begin{array}{c}20.44(5.75) \\
20(22)\end{array}$ & $\begin{array}{c}19.78(5.29) \\
20(18)\end{array}$ & 74.5 \\
\hline \multicolumn{8}{|c|}{ SUBJECTIVE COGNITIVE CONCERN } \\
\hline $\mathrm{SMI}^{\mathrm{a}} \mathrm{Q}^{\mathrm{a}}$ & 5 & $\begin{array}{c}2.05(1.43) \\
2(5)\end{array}$ & $\begin{array}{c}1.86(1.80) \\
1(5)\end{array}$ & 23.5 & $\begin{array}{c}1.83(1.79) \\
1.5(5)\end{array}$ & $\begin{array}{c}1.61(1.50) \\
1(4)\end{array}$ & 28 \\
\hline SMI-Q extended ${ }^{\mathrm{a}}$ & 20 & $\begin{array}{c}7.90(2.21) \\
8(7)\end{array}$ & $\begin{array}{c}7.19(2.14) \\
6(6)\end{array}$ & $18^{*}$ & $\begin{array}{c}7.67(2.57) \\
7(7)\end{array}$ & $\begin{array}{c}6.72(1.99) \\
6(7)\end{array}$ & 23 \\
\hline
\end{tabular}

Note. BTA $=$ Brief Test of Attention.LPS 50+ = Leistungsprüfsystem für $50-90$ jährige. MoCA = Montreal Cognitive Assessment. SMI-Q = Subjective Memory Impairment Questionnaire. TMT = Trail Making Test. VLMT = Verbaler Lern- und Merkfähigkeitstest. WMS VR = Wechsler Memory Scale (German version) subtest Visual Reproduction. a. Low scores indicate better performance. b. Statistical Value for the Wilcoxon Signed Rank Test for dependent samples. ${ }^{*} \mathrm{p} \leq 0.05 ;{ }^{* *} \mathrm{p} \leq 0.01 ;{ }^{* *} \mathrm{p} \leq 0.001$. 
Table 3. Comparison of pre- to posttest changes in outcome variables between both intervention groups.

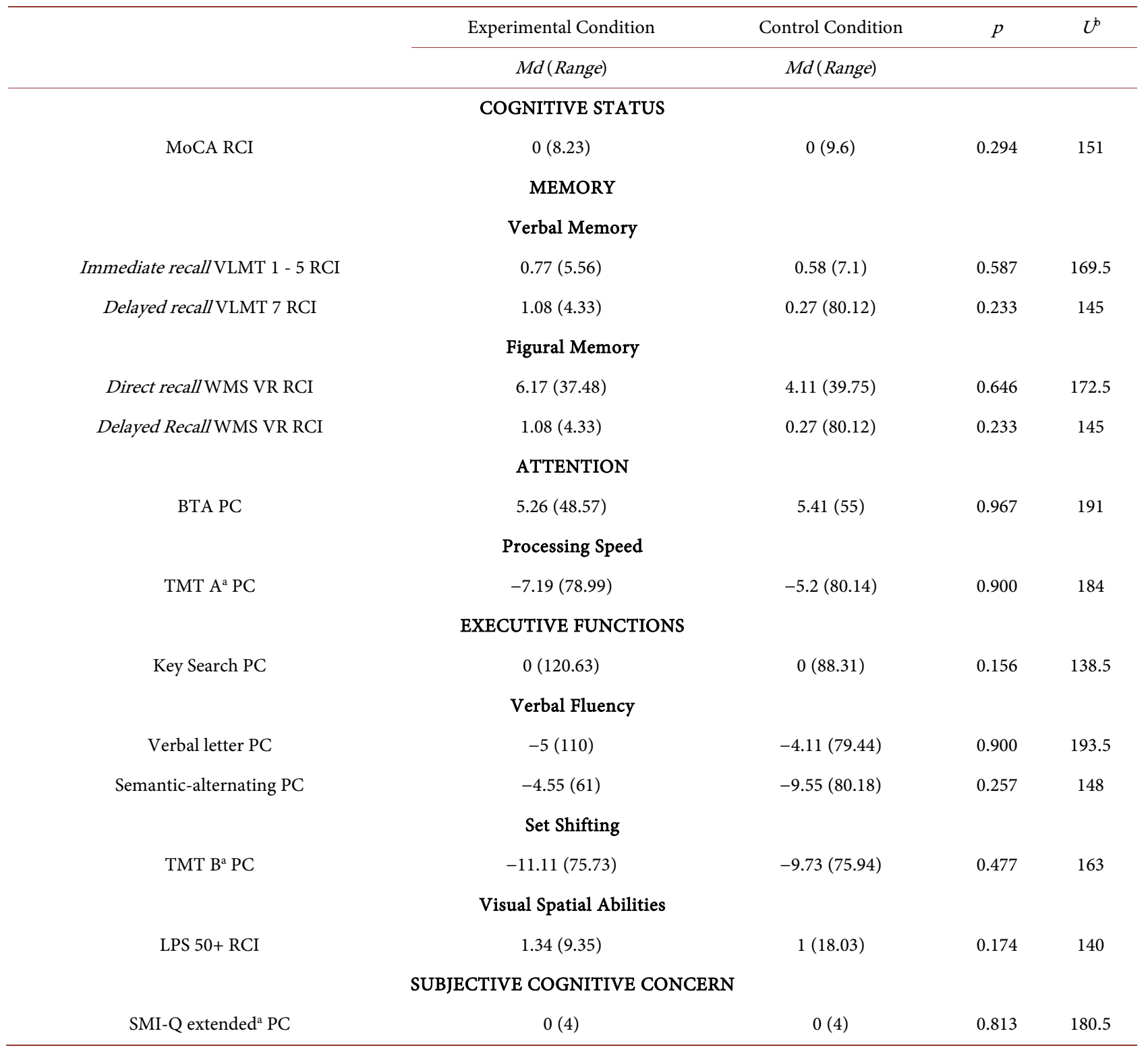

Note. BTA = Brief Test of Attention. LPS 50+ = Leistungsprüfsystem für 50 - 90 jährige. MoCA = Montreal Cognitive Assessment. PC = percentage change score. SMI-Q $=$ Subjective Memory Impairment Questionnaire. $\mathrm{RCI}=$ reliable change index. TMT $=$ Trail Making Test. VLMT $=$ Verbaler Lern- und Merkfähigkeits test. WMS VR $=$ Wechsler Memory Scale (German version) subtest Visual Reproduction. a. Low scores indicate positive direction. b. Statistical Value for the Mann-Whitney-U test with independent samples.

measure (all $p>0.05$ ). However, note that the power to detect group differences even for strong effects was generally low.

\subsubsection{Changes from Pre- to Posttest within Groups}

For the detection of effects from pre- to posttest (experimental group $n=21$, control group $n=18,2$-tailed $\alpha=0.05$ ), post-hoc power analysis revealed a power of $13.6 \%$ in the experimental and $12.2 \%$ in the control condition to detect small effects (Cohen's $d_{z} \geq 0.2$ ), a power of $56.6 \%$ in the experimental and $49.6 \%$ in the control condition to detect moderate effects (Cohen's $d_{z} \geq 0.5$ ) and a 
power of $92.5 \%$ in the experimental and $87.6 \%$ in the control condition to detect strong effects (Cohen's $d_{z} \geq 0.8$ ).

The results of the outcome measures pre- and post-intervention for both groups are presented in Table 2. On a descriptive level, posttest scores were consistently higher compared to pretest scores in the EG, whereas results in the CG were mixed. While in the EG, significantly higher values post- as compared to pre-test were found in verbal intermediate [VLMT $1-5 ; T(21)=163.5, p=$ $0.006, d_{z}=0.683$ ] and long term memory [VLMT 7; $T(21)=152.5, p=0.003, d_{z}$ $=0.750$ ], as well as in short term [WMS VR direct recall; $T(21)=162, p=0.007$, $d_{z}=0.668$ ], and long term figural memory [WMS VR delayed recall; $T(21)=$ $\left.186, p=.002, d_{z}=0.789\right]$, the EG significantly improved only in the WMS VR delayed recall condition $\left[T(18)=118.5, p=0.009, d_{z}=0.702\right]$. All effects were moderate to large.

Within the domain of executive functions, both groups significantly improved in set shifting with moderate effects as indicated by the TMT B [EG: $T(21)=52$, $p=0.027, d_{z}=0.526$; CG: $\left.T(18)=28, p=0.012, d_{z}=0.669\right]$. However, the CG showed lower scores at posttest in verbal fluency [RWT semantic alternating fluency; $\left.T(18)=37.5, p=0.036, d_{z}=0.536\right]$. Furthermore, only the EG significantly improved in visual-spatial functioning [LPS50+, subtest 9: $T(21)=186.5$, $p=0.013, d_{z}=0.605$ ], and SCC decreased [SMI-Q extended version: $T(21)=18$, $\left.p=0.027, d_{z}=0.526\right]$ - both with moderate effects. No other significant results were found.

\subsection{Predictor Analysis}

Assuming a maximum of nine predictors per model (based on $n=21$ participants in the EG), this study had $62 \%$ power to detect predictors of a model with at least $R^{2}=0.50(\alpha=0.05)$. The results of the predictor analyses are shown in Table S2 of the Supplementary Material. Main results are:

1) Low baseline performance in the particular tests were predictors for training gains in verbal intermediate (VLMT $1-5, \beta=-0.453$ ) and long term memory (VLMT 7, $\beta=-0.595$ ) as well as figural short (WMS VR direct recall, $\beta=$ -0.711 ) and long-term memory (WMS VR delayed recall, $\beta=-0.626$ ), executive functions as indicated by verbal fluency tasks (RWT letter fluency, $\beta=-0.467$ ), semantic-alternating fluency, $\beta=-0.476$ ) and set-shifting (TMT B, $\beta=-0.466$ ), attention (BTA $(\beta=-0.889)$ and processing speed (TMT A: $\beta=-0.72$ ), and visuospatial functioning (LPS $50+$, subtest $9, \beta=-0.461$ ).

2) Low SCC as measured with the SMI-Q extended version score was a predictor for gains in verbal intermediate memory (VLMT $1-5 ; \beta=-0.281$ ), executive functions as indicated by verbal fluency (RWT letter fluency, $\beta=$ -0.546 ), and attention (BTA, $\beta=-0.372$ ).

3) A good average grade for the intervention predicted gains in verbal intermediate (VLMT $1-5, \beta=-0.546$ ) and long term memory (VLMT 7, $\beta=$ $-0.513)$. 
4) High self-efficacy scores predicted improvement of figural memory (WMS VR direct recall, $\beta=0.355$ ).

5) High depression scores were predictive for better performance post training in processing speed (TMT A, $\beta=-0.368$ ).

6) Higher age was a negative predictor-in other words: younger age was a positive predictor-for gains in figural memory (WMS VR direct recall, $\beta=$ -0.774 ), and attention (BTA, $\beta=-0.246$ ).

7) Years of education did not have a predictive value in any of the analyses.

8) Female sex predicted gains in long-term figural memory (WMS VR delayed recall, $\beta=0.461$ ) and attention (BTA, $\beta=0.293$ ), while male sex predicted losses in set shifting (TMT B, $\beta=-0.351$ ).

9) Technology commitment led to inconsistent results. On the one hand, high technology commitment predicted gains in figural long term memory (WMS VR delayed recall, $\beta=0.623$ ). On the other hand, it predicted a negative influence on executive functions (TMT B, $\beta=0.400$; RWT letter fluency, $\beta=-0.406$ ), and speed of processing (TMT A, $\beta=0.275$ ).

\section{Discussion}

This study aimed at examining the effects of a CCT especially designed for older adults compared to an unspecific CCT in a group of healthy older adults. The main findings of the study are that (1) no Group $\times$ Time interaction effects were found for the CG versus the EG when RCIs and change scores from pre- to posttest were compared, but that (2) in within-group comparisons, the EG showed significant gains in verbal short and long-term memory, non-verbal short and long-term memory, set-shifting, visuospatial functions, and SCC, while the CG only benefitted in non-verbal long-term memory and set-shifting and even worsened in an alternating fluency task. Finally, (3) low cognitive baseline performance as well as lower SCC at baseline were the most consistent predictors of cognitive gains in the EG.

Although we were not able to find Group $\times$ Time interaction effects, the fact that substantially more gains were achieved in the CCT target intervention as elicited in the within-group comparisons allow the (tentative) conclusion that it was indeed more effective than the active control intervention. When interpreting these results one has to keep in mind that the effects of our target intervention might be underestimated for two reasons: first, an active control group was used. Although [11] did not find a difference between active and passive control treatments when analyzing CCT effects in cognitively healthy elderly, the meta-analysis conducted by [8] did find differences of effects in studies with active versus passive control treatments in executive-control and working memory training in older adults. Second, it can be assumed that the kind of active control treatment is relevant for the possibilities to find effects. In our study, the control intervention comprised an unspecific CCT which was not tailored to the group of healthy elderly, but which still trained a broad spectrum of functions (e.g. 
reading abilities, orthography, perception, concentration, visual-motor skills) and was cognitively challenging. Thus, the unspecific CCT as an active control intervention was similar to the target CCT, and larger differences might be expected with less similar control conditions that do not include cognitive tasks and which more likely do not yield any cognitive effects; and even stronger effects can be expected for comparisons with passive control groups. However, the usage of an active control intervention challenging the target intervention can be considered a quality criterion of the present study [33]. Thus, further studies with tailored programs for older adults and other control groups will have to test our hypothesis that such interventions are especially effective in this group. If effectiveness of (tailored) CCT for memory, visuospatial functions as well as executive functions (the latter of which was not found to be significantly trained with CCT in the meta-analysis conducted by [11] in healthy older adults will be further confirmed-all functions which are vulnerable in aging-this intervention form which is easy to administer and usually not cost-intensive would be a promising approach to support healthy cognitive aging.

The fact that low cognitive baseline performance was predictive for gains in various cognitive domains including verbal and non-verbal memory, executive functions, processing speed and visuospatial functioning is consistent with most, though not all [19], previous studies [17] [20] [21]. It has already been discussed that the lower range of a high-functioning sample can be improved more [20], and the neuropsychological scores of the overall group which are considerably below the maximum scores rule out ceiling effects even in the higher range of the sample. Therefore, CT seems to be suitable to strengthen cognitive domains that are lower or "weaker" in healthy individuals. On the other hand, individuals with high performance may need more challenging training programs to even maximise their functions. This aspect merits further investigation, and predictor analysis will be useful here and will help to tailor CT programs to specific target groups.

Our result that also lower SCC is predictive for cognitive gains in relevant domains (verbal memory, verbal fluency, and attention), is intriguing. SCC is regarded as a predictor for dementia development [63] and is associated with Alzheimer typical biomarkers [64]. Studies which examine the extent to which non-pharmacological interventions such as CT are effective to enhance cognition in individuals with SCC [65] and whether or not neural plasticity is already reduced compared to healthy older adults without SCC [66] have just begun. However, to the best of our knowledge, SCC has not been examined as a predictor of CT gains yet. Our results point to the possibility that SCC may be associated with a reduced cognitive plasticity and that individuals with SCC have less gains in various cognitive domains after multidomain CCT. Future studies with larger sample sizes will have to replicate and elaborate this notion.

Consistent with our hypothesis, motivation and self-efficacy were identified as positive predictors of training success in verbal and figural memory, respective- 
ly. Metacognitive and motivational measures were already identified as predictors for gains in objective memory measures in a strategic memory training in older adults [37]. The meta-analytic path analysis of [38] further underscores the importance and close interaction between self-efficacy, motivation and training success. In conclusion, individual characteristics and metacognitive attitudes should be taken into consideration when implementing a training program such as our CCT. Therefore, instructors and supervisors would do well to leverage self-efficacy and motivation at the beginning of the training period, for example by persuading trainees that they can succeed and profit from the training and presenting them with vicarious experiences [67].

The other results of our predictor analysis are less clear-cut. Regarding depression, the result that higher depression scores predicted better outcome in verbal memory and speed of processing was unexpected, as depression is regarded to reduce brain and cognitive plasticity [25] and, for example, has also been demonstrated to mediate the relationship between (low) cognitive scores and cognitive gains induced by a cognitive stimulation program in dementia patients [26]. However, it should be noted that clinically relevant depression scores and even mild symptoms were an exclusion criterion for our study sample, so that symptoms if present were minimal. One hypothesis for our findings could be that individuals with mild symptoms of depression may have been particularly motivated by the program and the attention they received by the experimenter during the study. This might have resulted in a reduction of depressive symptoms during the training period, leading to better test performance post training. Unfortunately, depression scores were not assessed after the training, so that this notion remains speculative and needs further investigation.

Regarding the influence of sociodemographic factors, the fact that female gender predicts gains in memory corroborates previous findings that women profit more from CT programs especially in the memory domain, although [34] found effects for verbal, not figural memory which fit better to the hypothesis of a "gender-specific cognitive reserve" [68], which assumes larger plasticity in verbal episodic memory in women. Thus, our finding that gains in non-verbal long-term memory, attention and set-shifting was predicted by female gender needs further investigation. The fact that higher age was a negative predictor for gains in (non-verbal) memory and attention is concordant with the notion that higher age is regarded to be associated with less brain and cognitive plasticity [25] and with other findings that younger age predict better training outcome of cognitive or memory training [69] [70] [71] [72], although conflicting data also exist [73] [74].

The inconsistent results regarding technology commitment as a predictor for gains in figural memory, but losses in executive functions and speed of processing are hard to interpret-even more so when the results of [29] are taken into account that computer familiarity (although a slightly different construct) was not predictive at all for the success of computer-based memory 
training. This topic needs further investigation.

Some limitations have to be kept in mind when interpreting the results. First, the small sample size in our pilot study limited the power to detect interaction effects between the two training groups and generally limit clear conclusions. Thus, further studies with larger samples are needed and might be able to demonstrate the possible favour of cognitive training programs that are tailored to the specific needs of healthy older adults. Second, the fact that a pilot version of the training program was used in which the automatic adjustment of difficulty levels had not been implemented yet and in which individuals had to follow concrete instructions to choose the adequate training levels, might have influenced the results. Thus, future studies will have to show whether the expectation that fully adaptive programs which lead the individual smoothly through the program will be more effective. Third, our study was only single-blind. While individuals who performed the training were blind to the program, the person who administered the neuropsychological test battery was not. Thus, although test battery was fully standardized, a bias is possible and should clearly be avoided in further studies. Fourth, it is not possible to define the specific efficacious elements in a multidomain training program and, in our case, differentiate the impact of the direct training from the psychoeducational elements. One important difference between the groups was that the experimental group included a video that explained effects of cognitive training, which might have promoted expectations and corresponding effects. Therefore, for future studies and to extract the effects of the direct training, the psychoeducational elements should be designed more similar between groups, especially regarding contents that could directly influence the training outcome via a placebo effect as for example information on the effectiveness of cognitive trainings. Another control group that only differs in the nature of the psychoeducational elements could further disentangle effects of the specifically targeted cognitive training intervention from psychoeducational effects. With regard to the fact that effects of specific cognitive training tasks in the programs cannot be derived, it is important to note that multidomain trainings rather than interventions focused on only one domain have been recommended for inducing lasting improvement in cognition in healthy older adults [5] [75] [76]. Fifth, no long term follow-up was performed in this study, as in many other cognitive training studies conducted with healthy older adults [4], which further limit the generalizability of our findings. As the ultimate goal is to prevent cognitive decline long-term in this group of people, this is an important aspect for further studies. Finally, as a more general remark, a recent review on the effectiveness of cognitive trainings [33] challenges the assumption of transfer effects to distantly related tasks and daily life cognitive performance, and even to closely related tasks. With our study, we are not able to make any conclusions whether or not effects on cognitive measures are also related to effects in every life. Therefore, measuring these transfer effects is a central aspect that should be faced in future studies [33]. 
The specific strength of our study is that, to our knowledge, this is the first RCT with CCT that was specifically developed for healthy older adults. Such programs which contain both training elements for those domains that are particularly vulnerable in higher age and psychoeducational elements promoting a lifestyle supporting healthy cognitive aging seem very important in an aging society with an increasing prevalence of dementia. A further strength that planning and reporting followed the recommendations of the CONSORT Statement for RCT [41] [42] [43].

\section{Conclusion}

In conclusion, although our hypothesis that a CCT especially tailored to the profile of healthy older adults would lead to better cognitive outcome compared to a non-tailored CCT in terms of significant interaction effects could not be verified, benefits in more cognitive domains in within-comparisons for the CCT indicate that this type of intervention may be a fruitful approach to support older adults in sustaining their cognitive level. More studies are needed to corroborate this notion and also to further specify which individuals have a high probability to benefit from such programs. SCC as a possible predictor for future cognitive decline will have to be considered in this research.

\section{Acknowledgements}

This research was conducted at the University of Vechta und the University Hospital of Cologne. We thank all participants for their interest in the study. We thank Tintenklex Legasthenie Software, Damp, Germany for providing the software for study purposes. We thank Kay Paluszak for his help with data collection. Furthermore, we gratefully acknowledge the support of Ann-Kristin Folkerts, Bernd-Josef Leisen, Mandy Roheger, Sabrina Blawath and the Senior Service Office in Bremen, Germany.

This work was supported by the Federal Ministry of Education and Research under Grant 16SV5917.

\section{References}

[1] Baltes, P.B. and Singer, T. (2001) Plasticity and the Ageing Mind: An Exemplar of the Bio-Cultural Orchestration of Brain and Behaviour. European Review, 9, 59-76. https://doi.org/10.1017/S1062798701000060

[2] Li, H.-J., Hou, X.-H., Liu, H.-H., Yue, C.-L., Lu, G.-M. and Zuo, X.-N. (2015) Putting Age-Related Task Activation into Large-Scale Brain Networks: A Meta-Analysis of $114 \mathrm{fMRI}$ Studies on Healthy Aging. Neuroscience \& Biobehavioral Reviews, 57, 156-174. https://doi.org/10.1016/j.neubiorev.2015.08.013

[3] Reuter-Lorenz, P.A. and Park, D.C. (2014) How Does It STAC Up? Revisiting the Scaffolding Theory of Aging and Cognition. Neuropsychology Review, 24, 355-370. https://doi.org/10.1007/s11065-014-9270-9

[4] Kelly, M.E., Loughrey, D., Lawlor, B.A., Robertson, I.H., Walsh, C. and Brennan, S. (2014) The Impact of Cognitive Training and Mental Stimulation on Cognitive and Everyday Functioning of Healthy Older Adults: A Systematic Review and Me- 
ta-Analysis. Ageing Research Reviews, 15, 28-43.

https://doi.org/10.1016/j.arr.2014.02.004

[5] Rebok, G.W., Ball, K., Guey, L.T., Jones, R.N., Kim, H.Y., King, J.W., et al. (2014) Ten-Year Effects of the Advanced Cognitive Training for Independent and Vital Elderly Cognitive Training Trial on Cognition and Everyday Functioning in Older Adults. Journal of the American Geriatrics Society, 62, 16-24.

https://doi.org/10.1111/jgs.12607

[6] Reijnders, J., van Heugten, C. and van Boxtel, M. (2013) Cognitive Interventions in Healthy Older Adults and People with Mild Cognitive Impairment: A Systematic Review. Ageing Research Reviews, 12, 263-275.

https://doi.org/10.1016/j.arr.2012.07.003

[7] Tardif, S. and Simard, M. (2011) Cognitive Stimulation Programs in Healthy Elderly: A Review. International Journal of Alzheimer's Disease, 2011, Article ID: 378934. https://doi.org/10.4061/2011/378934

[8] Karbach, J. and Verhaeghen, P. (2014) Making Working Memory Work a Meta-Analysis of Executive-Control and Working Memory Training in Older Adults. Psychological Science, 25, 2027-2037. https://doi.org/10.1177/0956797614548725

[9] Kueider, A.M., Parisi, J.M., Gross, A.L. and Rebok, G.W. (2012) Computerized Cognitive Training with Older Adults: A Systematic Review. PLoS ONE, 7, e40588. https://doi.org/10.1371/journal.pone.0040588

[10] Shah, T.M., Weinborn, M., Verdile, G., Sohrabi, H.R. and Martins, R.N. (2017) Enhancing Cognitive Functioning in Healthly Older Adults: A Systematic Review of the Clinical Significance of Commercially Available Computerized Cognitive Training in Preventing Cognitive Decline. Neuropsychology Review, 27, 62-80. https://doi.org/10.1007/s11065-016-9338-9

[11] Lampit, A., Hallock, H. and Valenzuela, M. (2014) Computerized Cognitive Training in Cognitively Healthy Older Adults: A Systematic Review and Meta-Analysis of Effect Modifiers. PLOS Medicine, 11, e1001756. https://doi.org/10.1371/journal.pmed.1001756

[12] Buckner, R.L. (2004) Memory and Executive Function in Aging and AD: Multiple Factors That Cause Decline and Reserve Factors That Compensate. Neuron, 44, 195-208. https://doi.org/10.1016/j.neuron.2004.09.006

[13] Kalbe, E. and Kessler, J. (2009) Gerontoneuropsychologie-Grundlagen und Pathologie. Lehrbuch der klinischen Neuropsychologie, 2, 789-819.

https://doi.org/10.1007/978-3-8274-2248-4_47

[14] Park, D.C. and Reuter-Lorenz, P. (2009) The Adaptive Brain: Aging and Neurocognitive Scaffolding. Annual Review of Psychology, 60, 173-196.

https://doi.org/10.1146/annurev.psych.59.103006.093656

[15] Buschert, V.C., Friese, U., Teipel, S.J., Schneider, P., Merensky, W., Rujescu, D., et al. (2011) Effects of a Newly Developed Cognitive Intervention in Amnestic Mild Cognitive Impairment and Mild Alzheimer's Disease: A Pilot Study. Journal of Alzheimer's Disease, 25, 679-694.

[16] Buschert, V.C., Giegling, I., Teipel, S.J., Jolk, S., Hampel, H., Rujescu, D., et al. (2012) Long-Term Observation of a Multicomponent Cognitive Intervention in Mild Cognitive Impairment. The Journal of Clinical Psychiatry, 73, e1492-8. https://doi.org/10.4088/JCP.11m07270

[17] Rahe, J., Becker, J., Fink, G.R., Kessler, J., Kukolja, J., Rahn, A., et al. (2015) Cognitive Training with and without Additional Physical Activity in Healthy Older Adults: Cognitive Effects, Neurobiological Mechanisms, and Prediction of Training 
Success. Frontiers in Aging Neuroscience, 7, 187. https://doi.org/10.3389/fnagi.2015.00187

[18] Petrelli, A., Kaesberg, S., Barbe, M.T., Timmermann, L., Fink, G.R., Kessler, J., et al. (2014) Effects of Cognitive Training in Parkinson's Disease: A Randomized Controlled Trial. Parkinsonism \& Related Disorders, 20, 1196-1202. https://doi.org/10.1016/j.parkreldis.2014.08.023

[19] Fairchild, J., Friedman, L., Rosen, A. and Yesavage, J. (2013) Which Older Adults Maintain Benefit from Cognitive Training? Use of Signal Detection Methods to Identify Long-Term Treatment Gains. International Psychogeriatrics, 25, 607-616. https://doi.org/10.1017/S1041610212002049

[20] Whitlock, L.A., McLaughlin, A.C. and Allaire, J.C. (2012) Individual Differences in Response to Cognitive Training: Using a Multi-Modal, Attentionally Demanding Game-Based Intervention for Older Adults. Computers in Human Behavior, 28, 1091-1096. https://doi.org/10.1016/j.chb.2012.01.012

[21] Peretz, C., Korczyn, A.D., Shatil, E., Aharonson, V., Birnboim, S. and Giladi, N. (2011) Computer-Based, Personalized Cognitive Training versus Classical Computer Games: A Randomized Double-Blind Prospective Trial of Cognitive Stimulation. Neuroepidemiology, 36, 91-99. https://doi.org/10.1159/000323950

[22] Erickson, K.I., Miller, D.L. and Roecklein, K.A. (2012) The Aging Hippocampus: Interactions between Exercise, Depression, and BDNF. The Neuroscientist, 18, 82-97. https://doi.org/10.1177/1073858410397054

[23] Voss, M.W., Erickson, K.I., Prakash, R.S., Chaddock, L., Kim, J.S., Alves, H., et al. (2013) Neurobiological Markers of Exercise-Related Brain Plasticity in Older Adults. Brain, Behavior, and Immunity, 28. 90-99. https://doi.org/10.1016/j.bbi.2012.10.021

[24] Bäckman, L. and Forsell, Y. (1994) Episodic Memory Functioning in a Community-Based Sample of Old Adults with Major Depression: Utilization of Cognitive Support. Journal of Abnormal Psychology, 103, 361-370. https://doi.org/10.1037/0021-843X.103.2.361

[25] Pascual-Leone, A., Freitas, C., Oberman, L., Horvath, J.C., Halko, M., Eldaief, M., et al. (2011) Characterizing Brain Cortical Plasticity and Network Dynamics across the Age-Span in Health and Disease with TMS-EEG and TMS-fMRI. Brain Topography, 24, 302-315. https://doi.org/10.1007/s10548-011-0196-8

[26] Middelstädt, J., Folkerts, A.-K., Blawath, S. and Kalbe, E. (2016) Cognitive Stimulation for People with Dementia in Long-Term Care Facilities: Baseline Cognitive Level Predicts Cognitive Gains, Moderated by Depression. Journal of Alzheimer's Disease, 54, 253-268. https://doi.org/10.3233/JAD-160181

[27] Smith, B. (2013) Depression and Motivation. Phenomenology and the Cognitive Sciences, 12, 615-635. https://doi.org/10.1007/s11097-012-9264-0

[28] Nestler, E.J., Barrot, M., DiLeone, R.J., Eisch, A.J., Gold, S.J. and Monteggia, L.M. (2002) Neurobiology of Depression. Neuron, 34, 13-25. https://doi.org/10.1016/S0896-6273(02)00653-0

[29] Bottiroli, S. and Cavallini, E. (2009) Can Computer Familiarity Regulate the Benefits of Computer-Based Memory Training in Normal Aging? A Study with an Italian Sample of Older Adults. Aging, Neuropsychology, and Cognition, 16, 401-418. https://doi.org/10.1080/13825580802691763

[30] Graessel, E., Stemmer, R., Eichenseer, B., Pickel, S., Donath, C., Kornhuber, J., et al. (2011) Non-Pharmacological, Multicomponent Group Therapy in Patients with Degenerative Dementia: A 12-Month Randomized, Controlled Trial. BMC Medi- 
cine, 9, 129. https://doi.org/10.1080/13825580802691763

[31] Binetti, G., Moretti, D.V., Scalvini, C., Giovanni, G., Verzeletti, C., Mazzini, F., et al. (2013) Predictors of Comprehensive Stimulation Program Efficacy in Patients with Cognitive Impairment. Clinical Practice Recommendations. International Journal of Geriatric Psychiatry, 28, 26-33. https://doi.org/10.1002/gps.3785

[32] Aguirre, E., Hoare, Z., Streater, A., Spector, A., Woods, B., Hoe, J., et al. (2013) Cognitive Stimulation Therapy (CST) for People with Dementia-Who Benefits Most? International Journal of Geriatric Psychiatry, 28, 284-290. https://doi.org/10.1002/gps.3823

[33] Simons, D.J., Boot, W.R., Charness, N., Gathercole, S.E., Chabris, C.F., Hambrick, D.Z., et al. (2016) Do "Brain-Training" Programs Work? Psychological Science in the Public Interest, 17, 103-186. https://doi.org/10.1177/1529100616661983

[34] Rahe, J., Liesk, J., Rosen, J.B., Petrelli, A., Kaesberg, S., Onur, O.A., et al. (2015) Sex Differences in cognitive Training Effects of Patients with Amnestic Mild Cognitive Impairment. Aging, Neuropsychology, and Cognition, 22, 620-638. https://doi.org/10.1080/13825585.2015.1028883

[35] Olazaran, J., Muniz, R., Reisberg, B., Peña-Casanova, J., Del Ser, T., Cruz-Jentoft, A., et al. (2004) Benefits of Cognitive-Motor Intervention in MCI and Mild to Moderate Alzheimer Disease. Neurology, 63, 2348-2353. https://doi.org/10.1212/01.WNL.0000147478.03911.28

[36] Christoph, R.T., Schoenfeld Jr, G.A. and Tansky, J.W. (1998) Overcoming Barriers to Training Utilizing Technology: The Influence of Self-Efficacy Factors on Multimedia-Based Training Receptiveness. Human Resource Development Quarterly, 9, 25-38. https://doi.org/10.1002/hrdq.3920090104

[37] Carretti, B., Borella, E., Zavagnin, M. and De Beni, R. (2011) Impact of Metacognition and Motivation on the Efficacy of Strategic Memory Training in Older Adults: Analysis of Specific, Transfer and Maintenance Effects. Archives of Gerontology and Geriatrics, 52, e192-e197. https://doi.org/10.1016/j.archger.2010.11.004

[38] Colquitt, J.A., LePine, J.A. and Noe, R.A. (2000) Toward an Integrative Theory of Training Motivation: A Meta-Analytic Path Analysis of 20 Years of Research. Journal of Applied Psychology, 85, 678-707. https://doi.org/10.1037/0021-9010.85.5.678

[39] Jessen, F., Wiese, B., Bachmann, C., Eifflaender-Gorfer, S., Haller, F., Kölsch, H., et al. (2010) Prediction of Dementia by Subjective Memory Impairment: Effects of Severity and Temporal Association with Cognitive Impairment. Archives of General Psychiatry, 67, 414-422. https://doi.org/10.1001/archgenpsychiatry.2010.30

[40] Jessen, F., Wiese, B., Bickel, H., Eiffländer-Gorfer, S., Fuchs, A., Kaduszkiewicz, H., et al. (2011) Prediction of Dementia in Primary Care Patients. PLoS ONE, 6, e16852. https://doi.org/10.1371/journal.pone.0016852

[41] Boutron, I., Moher, D., Altman, D.G., Schulz, K.F. and Ravaud, P. (2008) Extending the CONSORT Statement to Randomized Trials of Nonpharmacologic Treatment: Explanation and Elaboration. Annals of Internal Medicine, 148, 295-309. https://doi.org/10.7326/0003-4819-148-4-200802190-00008

[42] Moher, D., Hopewell, S., Schulz, K.F., Montori, V., Gotzsche, P.C., Devereaux, P., et al. (2012) CONSORT 2010 Explanation and Elaboration: Updated Guidelines for Reporting Parallel Group Randomised Trials. International Journal of Surgery, 10, 28-55. https://doi.org/10.1016/j.ijsu.2011.10.001

[43] Schulz, K.F., Altman, D.G. and Moher, D. (2010) CONSORT 2010 Statement: Updated Guidelines for Reporting Parallel Group Randomised Trials. BMC Medicine, 


\section{8, 18. https://doi.org/10.1186/1741-7015-8-18}

[44] World Medical Association Declaration of Helsinki (1997) Recommendations Guiding Physicians in Biomedical Research Involving Human Subjects. Journal of the American Medical Association, 227, 925-926

[45] Nasreddine, Z.S., Phillips, N.A., Bédirian, V., Charbonneau, S., Whitehead, V., Collin, I., et al. (2005) The Montreal Cognitive Assessment, MoCA: A Brief Screening Tool for Mild Cognitive Impairment. Journal of the American Geriatrics Society, 53, 695-699. https://doi.org/10.1111/j.1532-5415.2005.53221.x

[46] Beck, A.T., Steer, R.A. and Brown, G.K. (1996) Beck Depression Inventory-II. San Antonio, 78, 490-498.

[47] Baller, G., Kalbe, E., Kaesberg, S. and Kessler, J. (2010) NEUROvitalis. Neuropsychologisches Gruppentraining. Prolog, Cologne.

[48] Göbel, S., Salvatore, L. and Konrad, R. (2008) StoryTec: A Digital Storytelling Platform for the Authoring and Experiencing of Interactive and Non-Linear Stories. International Conference on Automated Solutions for Cross Media Content and Multi-Channel Distribution, AXMEDIS 08, Florence, 17-19 November 2008 103-110.

[49] Reuter, C., Göbel, S. and Steinmetz, R. (2014) A Collection of Collaborative Player Interaction Patterns. TU Darmstadt, Multimedia Communcations Lab.

[50] Helmstaedter, C., Lendt, M. and Lux, S. (2001) VLMT: Verbaler Lern- und Merkfähigkeitstest. Beltz Test, Göttingen.

[51] Petermann, F. and Lepach, A. (2012) Wechsler Memory Scale-Fourth Edition (WMS-IV) Manual zur Durchführung und Auswertung. Deutsche Übersetzung und Adaptation der WMS-IV von David Wechsler. Pearson Assessment, Frankfurt/Main.

[52] Schretlen, D. (1997) Brief Test of Attention (BTA). Psychological Assessment Resources, Inc., Florida.

[53] Reitan, R.M. (1992) Trail Making Test: Manual for Administration and Scoring. Reitan Neuropsychology Laboratory, Length.

[54] Tombaugh, T.N. (2004) Trail Making Test A and B: Normative Data Stratified by Age and Education. Archives of Clinical Neuropsychology, 19, 203-214. https://doi.org/10.1016/S0887-6177(03)00039-8

[55] Aschenbrenner, S., Tucha, O. and Lange, K.W. (2000) Regensburger Wortflüssigkeits-Test. RWT, Hogrefe, Verlag für Psychologie.

[56] Wilson, B.A., Evans, J.J., Alderman, N., Burgess, P.W. and Emslie, H. (1997) Behavioural Assessment of the Dysexecutive Syndrome. In: Rabbitt, P., Ed., Methodology of Frontal and Executive Function, Psychology Press, East Sussex, 239-250.

[57] Sturm, W., Willmes, K. and Horn, W. (1993) Leistungsprüfungssystem für 50-90 jährige (LPS 50+). Hogrefe, Verlag für Psychologie, Handanweisung.

[58] Neyer, F.J., Felber, J. and Gebhardt, C. (2012) Entwicklung und Validierung einer Kurzskala zur Erfassung von Technikbereitschaft. Diagnostica, 58, 87-99. https://doi.org/10.1026/0012-1924/a000067

[59] Jerusalem, M. and Schwarzer, R. (1999) Skala zur allgemeinen Selbstwirksamkeitserwartung Skalen zur Erfassung von Lehrer-und Schülermerkmalen. Dokumentation der psychometrischen Verfahren im Rahmen der Wissenschaftlichen Begleitung des Modellversuchs Selbstwirksame Schulen. Freie Universität Berlin, Berlin.

[60] Erdfelder, E., Faul, F. and Buchner, A. (1996) GPOWER: A General Power Analysis Program. Behavior Research Methods, Instruments, \& Computers, 28, 1-11. https://doi.org/10.3758/BF03203630 
[61] Jacobson, N.S. and Truax, P. (1991) Clinical Significance: A Statistical Approach to Defining Meaningful Change in Psychotherapy Research. Journal of Consulting and Clinical Psychology, 59, 12-19. https://doi.org/10.1037/0022-006X.59.1.12

[62] Field, A. (2013) Discovering Statistics Using IBM SPSS Statistics. Sage, London.

[63] Jessen, F., Amariglio, R.E., Van Boxtel, M., Breteler, M., Ceccaldi, M., Chételat, G., et al. (2014) A Conceptual Framework for Research on Subjective Cognitive Decline in Preclinical Alzheimer's Disease. Alzheimer's \& Dementia, 10, 844-852. https://doi.org/10.1016/j.jalz.2014.01.001

[64] Jessen, F. (2014) Subjective and Objective Cognitive Decline at the Pre-Dementia Stage of Alzheimer's Disease. European Archives of Psychiatry and Clinical Neuroscience, 264, 3-7. https://doi.org/10.1007/s00406-014-0539-Z

[65] Smart, C.M., Karr, J.E., Areshenkoff, C.N., Rabin, L.A., Hudon, C., Gates, N., et al. (2017) Non-Pharmacologic Interventions for Older Adults with Subjective Cognitive Decline: Systematic Review, Meta-Analysis, and Preliminary Recommendations. Neuropsychology Review, 1-13.

[66] Engvig, A., Fjell, A.M., Westlye, L.T., Skaane, N.V., Dale, A.M., Holland, D., et al. (2014) Effects of Cognitive Training on Gray Matter Volumes in Memory Clinic Patients with Subjective Memory Impairment. Journal of Alzheimer's Disease, 41, 779-791.

[67] Gist, M.E. and Mitchell, T.R. (1992) Self-Efficacy: A Theoretical Analysis of Its Determinants and Malleability. Academy of Management Review, 17, 183-211.

[68] Beinhoff, U., Tumani, H., Brettschneider, J., Bittner, D. and Riepe, M. (2008) Gender-Specificities in Alzheimer's Disease and Mild Cognitive Impairment. Journal of Neurology, 255, 117-122. https://doi.org/10.1007/s00415-008-0726-9

[69] Yesavage, J.A., Sheikh, J.I., Friedman, L. and Tanke, E. (1990) Learning Mnemonics: Roles of Aging and Subtle Cognitive Impairment. Psychology and Aging, 5, 133-137. https://doi.org/10.1037/0882-7974.5.1.133

[70] Verhaeghen, P., Marcoen, A. and Goossens, L. (1992) Improving Memory Performance in the Aged through Mnemonic Training: A Meta-Analytic Study. Psychology and Aging, 7, 242-251. https://doi.org/10.1037/0882-7974.7.2.242

[71] Rebok, G.W., Langbaum, J.B., Jones, R.N., Gross, A.L., Parisi, J.M., Spira, A.P., et al. (2013) Memory Training in the ACTIVE Study: How Much Is Needed and Who Benefits? Journal of Aging and Health, 25, 21S-42S. https://doi.org/10.1177/0898264312461937

[72] Brooks, J.O., Friedman, L., Pearman, A.M., Gray, C. and Yesavage, J.A. (1999) Mnemonic Training in Older Adults: Effects of Age, Length of Training, and Type of Cognitive Pretraining. International Psychogeriatrics, 11, 75-84. https://doi.org/10.1017/S1041610299005608

[73] Dorfman, C.R. and Ager, C.L. (1989) Memory and Memory Training: Some Treatment Implications for Use with the Well Elderly. Physical \& Occupational Therapy in Geriatrics, 7, 21-42.

[74] Rasmusson, D.X., Rebok, G.W., Bylsma, F.W. and Brandt, J. (1999) Effects of Three Types of Memory Training in Normal Elderly. Aging, Neuropsychology, and Cognition, 6, 56-66. https://doi.org/10.1076/anec.6.1.56.790

[75] Cheng, Y., Wu, W., Feng, W., Wang, J., Chen, Y., Shen, Y., et al. (2012) The Effects of Multi-Domain versus Single-Domain Cognitive Training in Non-Demented Older People: A Randomized Controlled Trial. BMC Medicine, 10, 30. https://doi.org/10.1186/1741-7015-10-30 
[76] Gates, N. and Valenzuela, M. (2010) Cognitive Exercise and Its Role in Cognitive Function in Older Adults. Current Psychiatry Reports, 12, 20-27.

https://doi.org/10.1007/s11920-009-0085-y 


\section{Online Supplementary Material}

Manuscript "Computerized cognitive training in healthy older adults: baseline cognitive level and subjective cognitive concerns predict training outcome" by Kalbe et al.

Exercises: Experimental intervention "Neuro VitAALis"

Exercise "Category memory" (Example in Figure $S 1$ )

Mainly trained domain: Memory

Table S1. Characteristics of the experimental and the control intervention.

\begin{tabular}{|c|c|c|}
\hline & Experimental intervention & Control intervention \\
\hline \multirow{3}{*}{$\begin{array}{l}\text { Frequency, } \\
\text { intensity }\end{array}$} & \multicolumn{2}{|l|}{ For both trainings: } \\
\hline & \multicolumn{2}{|l|}{18 units à 40 - 45 minutes ( 3 x/week) } \\
\hline & \multicolumn{2}{|l|}{ For both trainings: } \\
\hline \multirow[t]{4}{*}{ Elements } & \multirow{2}{*}{\multicolumn{2}{|c|}{$\begin{array}{l}\text { - } \quad \text { psychoeducational videos } \\
\text { - } \quad \text { advice of the day }\end{array}$}} \\
\hline & & \\
\hline & Memory & Reading \\
\hline & Executive functions & Spelling \\
\hline \multirow{4}{*}{$\begin{array}{l}\text { Main domains } \\
\text { trained }\end{array}$} & Complex attention & Attention \\
\hline & Spatial cognition & Visual-spatial perception \\
\hline & Language & Visual-motor skills \\
\hline & 1) Exercise either memory or executive functions (20 min) & 1) Exercise (20 min) \\
\hline \multirow{11}{*}{ Typical session } & 2) Psychoeducational video (10 - $15 \mathrm{~min})$ & 2) Psychoeducational video (10 - $15 \mathrm{~min})$ \\
\hline & 3) Exercise: complex attention, spatial cognition, or language (10 min) & 3) Exercise (10 min) \\
\hline & 4) Advice of the day (5 min) & 4) Advice of the day (5 min) \\
\hline & 1) Introduction & 1) Good sleep \\
\hline & 2) Effectiveness of cognitive training & 2) Myths about sports \\
\hline & 3) The aging brain from a biological perspective & 3) Extinction learning \\
\hline & 4) Cognition in ageing & 4) Weight regulation I \\
\hline & 5) Memory and age & 5) Good resolutions \\
\hline & 6) Attention and memory & 6) Sleep \\
\hline & 7) External mnemonic strategies & 7) Romantic relationships \\
\hline & 8) Internal mnemonic strategies & 8) Risk factor: Overweight \\
\hline \multirow{10}{*}{$\begin{array}{l}\text { Topics of the } \\
\text { psychoeducational } \\
\text { videos per session }\end{array}$} & 9) Memorizing names and faces & 9) Health applications \\
\hline & 10) Working memory & 10) Myths about sleep \\
\hline & 11) Planning aids for everyday life & 11) Nutrition \\
\hline & 12) Successful aging & 12) Drinking \\
\hline & 13) Risk factors of cognitive reduction & 13) Memory traces \\
\hline & 14) Protective factor: Nutrition & 14) Sitting \\
\hline & 15) Protective factor: Exercise & 15) Relationships \\
\hline & 16) Protective factor: Lifestyle & 16) Weight regulation II \\
\hline & 17) The importance of the image of old age & 17) Sleeping pills \\
\hline & 18) Outlook to my further NeuroCare training & 18) Time management \\
\hline
\end{tabular}




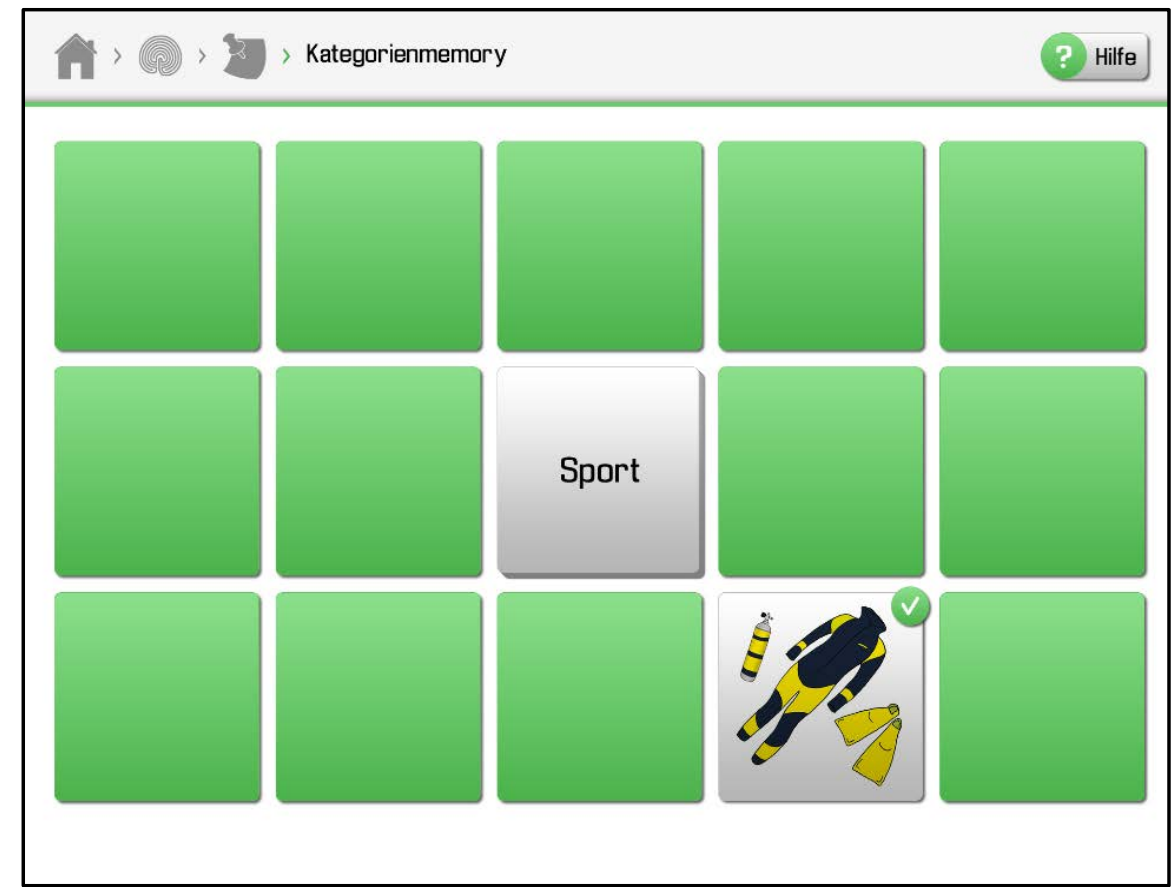

Figure S1. Exercise "Category memory” (in German language).

The presented visual stimuli consist of eight umbrella term cards (e.g. profession) and 80 picture cards. The exercise sequence follows the same principle as a classic memory game. In the middle lies a card pile with an umbrella term. The top card is disclosed; around this card lie hidden picture cards. The first picture card is then to be uncovered/turned over and examined to see whether it matches the umbrella term. In the case of a match, both cards are laid aside and a new umbrella term is revealed. If the uncovered card does not match the umbrella term, the card is turned upside down again and the umbrella term stays unchanged. At higher difficulty levels, individual or combined parameters of difficulty increase: Duration of the game, number of hidden cards, frequency of changing the umbrella card, specification of the search request of a category towards a single concrete picture card. There are 24 difficulty levels for this exercise.

\section{Exercise "Daily plan" (Example in Figure S2)}

\section{Mainly trained domain: executive functions}

At the beginning of the task a daily calendar with time categories is presented. On the right side, there are different activities displayed that should be classified into the daily schedule following specific rules. The classification of activities not only depends on a predefined time schedule but also on an order of succession of activities that needs to be considered. Difficulty variations result from the following conditions: Individual timeslots in the schedule are blocked, while others may be occupied twice, appointments are subject to a fixed duration, appointments are only shown once and then must be kept in mind/remembered until they are processed. There are 14 difficulty variations/levels for this exercise. 


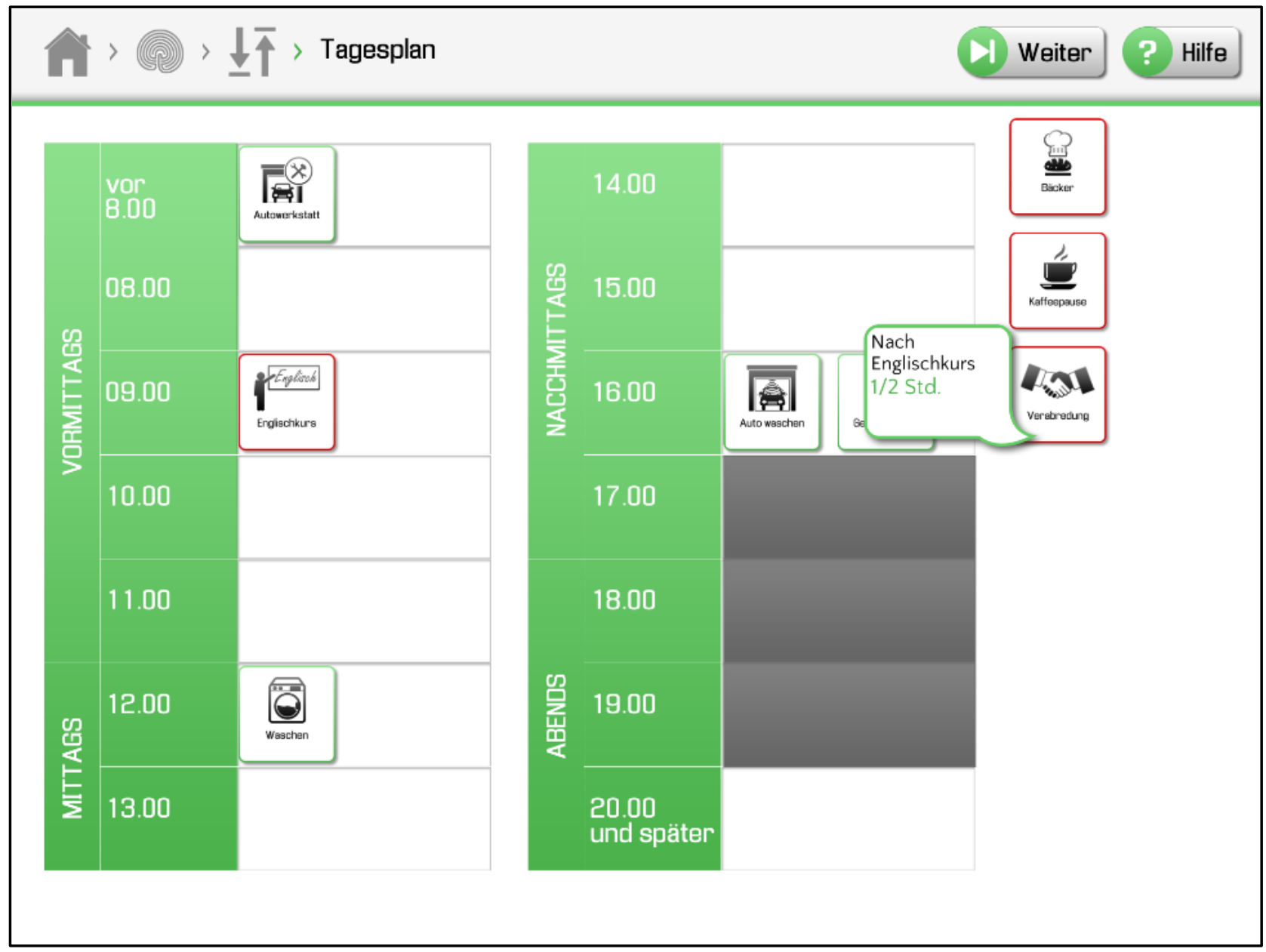

Figure S2. Exercise "Daily plan" (in German language).

Exercise "Lateral thinking" (Example in Figure S3)

Mainly trained domain: Complex attention

The exercise is composed of varying stimuli in different colors and shapes moving from the left to the right side of the screen. If a stimuli fits the displayed rule/criteria (color and shape) it has to be selected before reaching a red marked area on the right side of the screen. At higher levels, attention must also be given to the patterns of the stimuli. Difficulty variations result from the following conditions: Density of stimuli, number (and combination) of features that have to be considered before selection, number and speed of the change of rules/criteria, presentation speed of the stimuli. There are 14 difficulty variations for this exercise.

\section{Exercise "City map" (Example in Figure S4)}

\section{Mainly trained domain: Spatial cognition}

The task is composed of two parts: The first part of the task consists in the completion of a map by inserting matching parts. The cards have to be selected and aligned in order to fit the layout of a street map. In the second part it is required to determine the shortest possible distance from a certain starting point, 


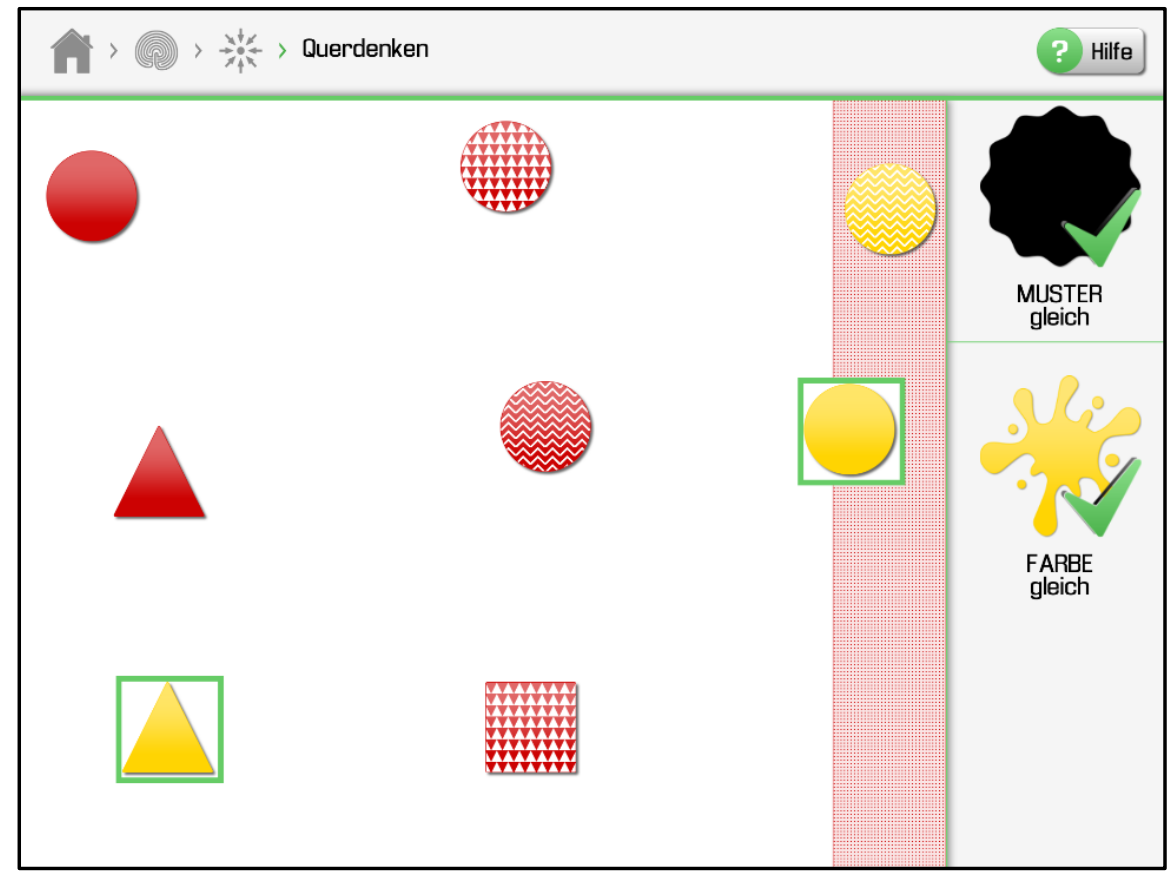

Figure S3. Exercise "Lateral thinking". In the left part of the screen, criteria are displayed in German: "Muster gleich" for "same pattern" and "Farbegleich" for "same color".

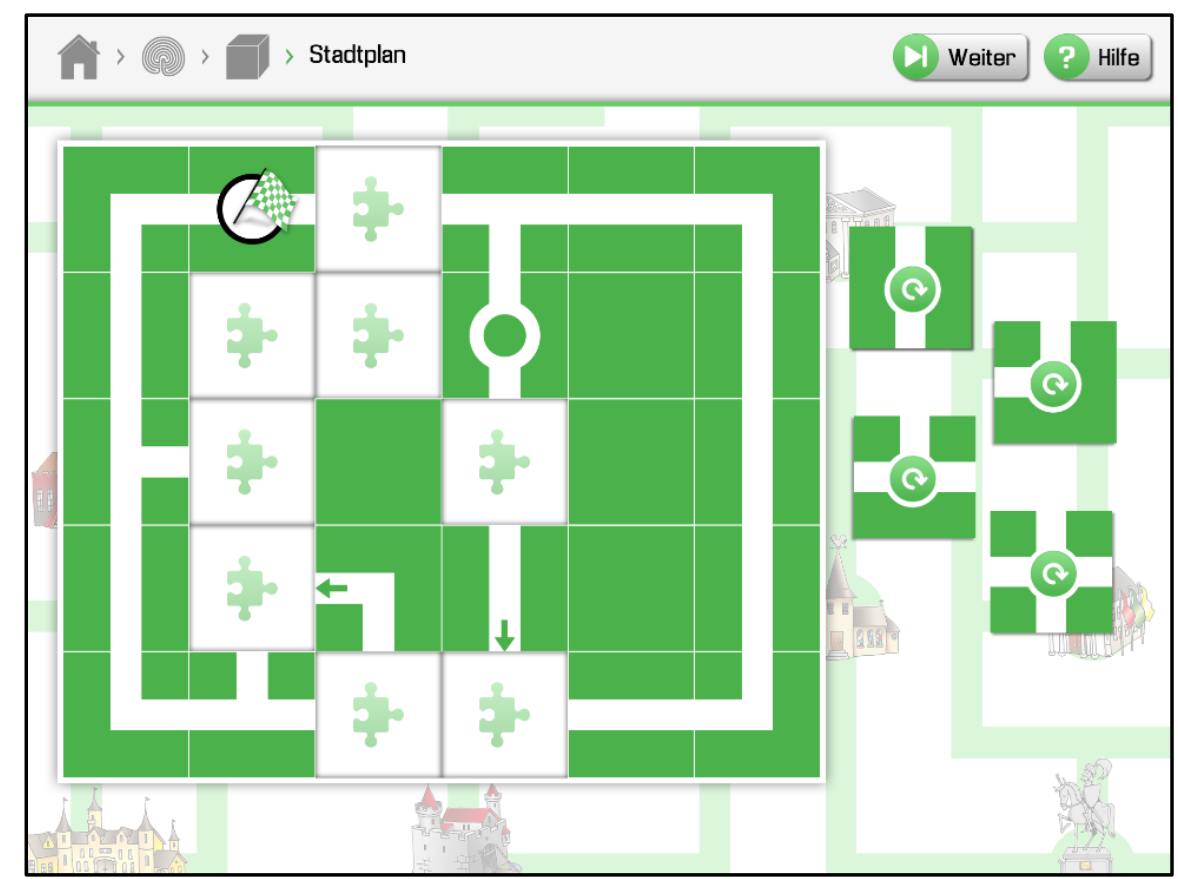

Figure S4. Exercise “City map” (in German language).

through various intermediate stations, to a destination point. The task difficulty is simultaneously increased in both conditions. The variations of the first tasks are: number of cards that need to be inserted and correctly aligned prior to insertion, completion of the map after a memorizing phase. The difficulty parameters of the second part change as follows: Number of intermediate stations, 
impairment of the feasible direction induced by one-way streets. There are 16 difficulty variations for this exercise.

\section{Exercise: "Word fluency" (Example in Figure S5)}

Mainly trained domain: Language

Language is trained through three different exercises of increasing complexity. There are three difficulty variations for each exercise. The first task requires the user to match terms to defined categories. The difficulty of the task is increased
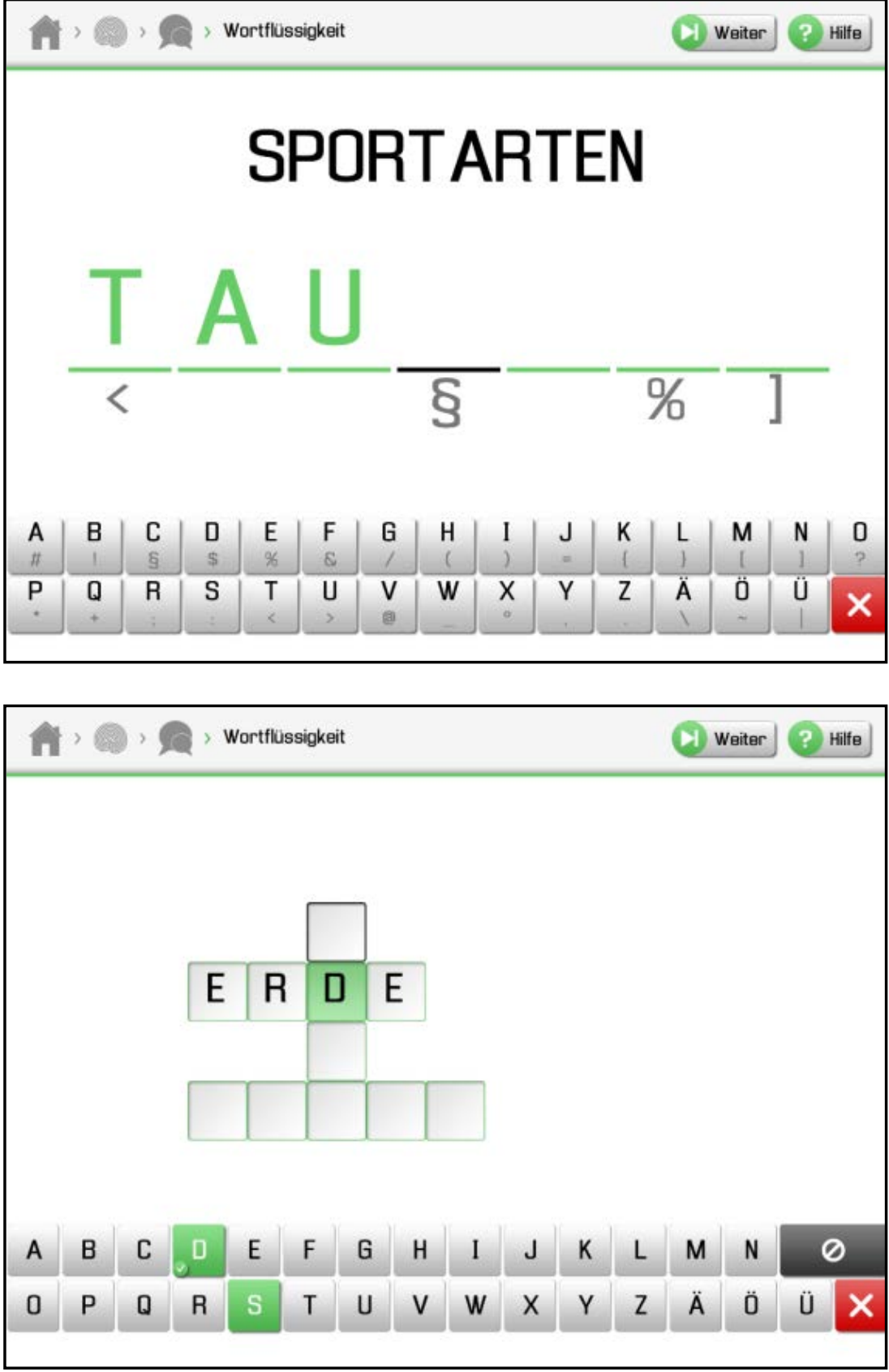

Figure S5. Exercise "Word fluency". First example: sports ("Sportarten” in German) and the first three letters of the German word for diving ("tauchen"). Second example: Blank crossword puzzle including the first word "Erde", which is German for "earth". 
through specification of the categories (e.g. insect instead of animal). During the next task, the user has to contrive words matching a specific category, the number of clues given decreases alongside the increase of task difficulty. The third and most complex exercise is a blank field of a crossword puzzle in which the user has to fill in all cases with a term without contradictions. Each task has a specific amount of letters that the participant is required to use. Task difficulty increases by number of the blank fields to fill and number of compulsory letters.

\section{Exercises: Control intervention "Tintenklex" \\ Example: Exercise "Word rain" (Example in Figure S6)}

Mainly trained domain: Spelling, speed of processing

The word that is initially displayed is to be composed with letters, moving from the top of the screen to the bottom. The user solves the exercise by moving each letter into the right column before it reaches the bottom. The user has the possibility to adapt the speed.

\section{Exercise: "Griddle" (Example in Figure S7)}

Mainly trained domain: Reading/attention

Words which can be displayed diagonally, vertically and horizontally, forwards and backwards have to be found.
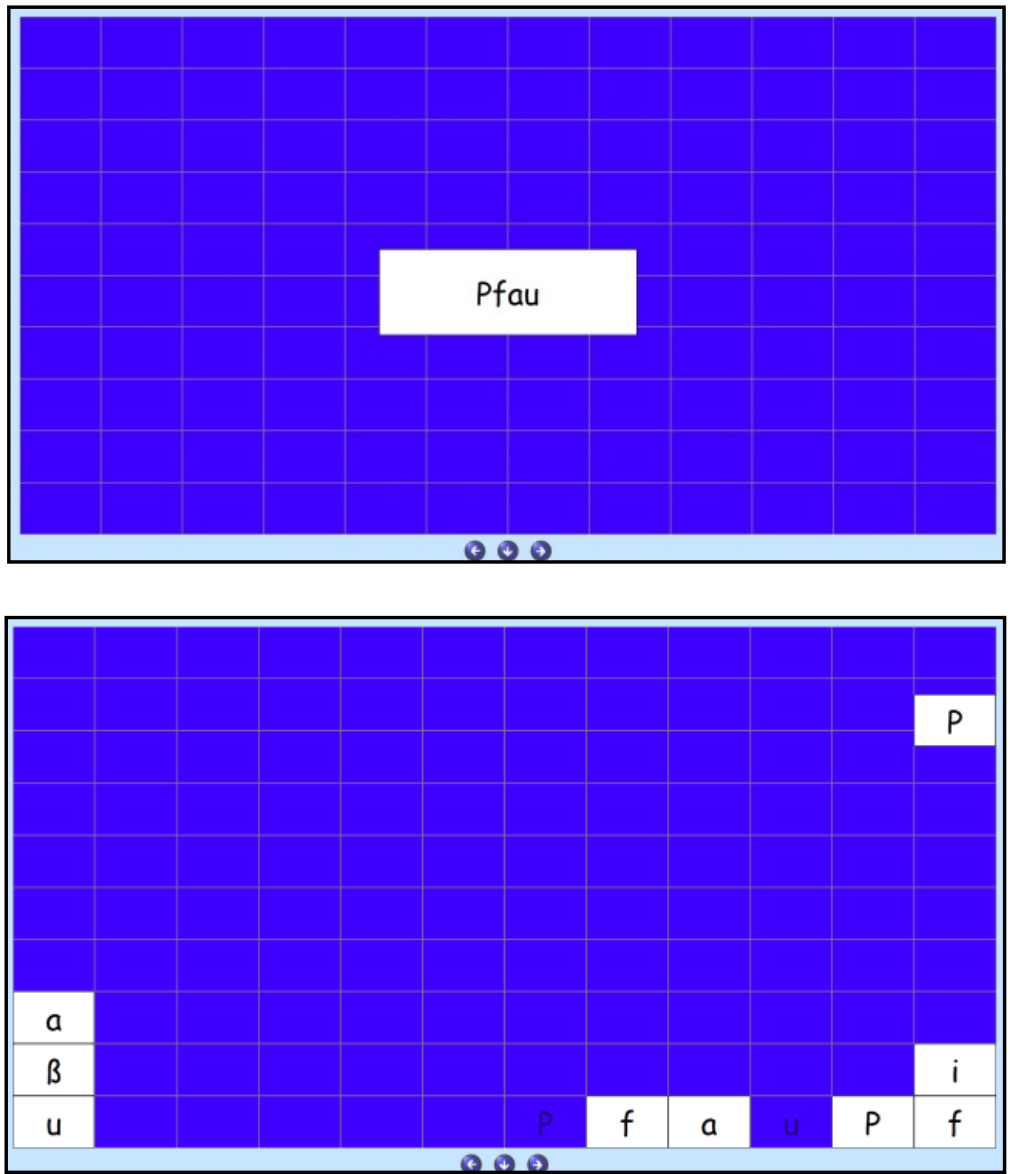

Figure S6. Exercise "Word rain" (in German language). Example: the German word "Pfau" for peacock. 


\section{Exercise: "Klexsklick" (Example in Figure S8)}

Mainly trained domain: Visuo-spatial processing, reading

At the right eight words are displayed. In the middle of the screen is a grid of $5 \times 6$ fields, and one field after the other is revealed until the user recognizes the symbol and clicks the field with the matching word.

\section{Exercise: "Labyrinth" (Example in Figure S9)}

Mainly trained domain: Visual-motor processing

The task is part of three exercise-units with a duration of ten minutes. The user has to solve a labyrinth by moving the red dot via the exit.

\section{Exercise: "Different pictures" (Example in Figure S10)}

Mainly trained domain: visuospatial processing, attention

The task is part of three exercise-units with a duration of ten minutes. The user has to compare the two images, find 10 differences and click on the appropriate places on one of the fields.

\begin{tabular}{|c|c|c|c|c|c|c|c|c|c|c|c|}
\hline$E$ & $L$ & $C$ & $H$ & $x$ & $E$ & $E$ & $H$ & $U$ & $K$ & $L$ & $S$ \\
\hline $\mathrm{H}$ & $A$ & $G$ & $E$ & I & $F$ & $D$ & $R$ & $E$ & $F$ & $P$ & $G$ \\
\hline$F$ & $H$ & $C$ & $S$ & I & $F$ & $L$ & $A$ & W & W & V & $\ddot{A}$ \\
\hline$\ddot{A}$ & $Q$ & $k$ & $H$ & Ö & $A$ & $\mathrm{~T}$ & $E$ & W & Ö & $L$ & $y$ \\
\hline$\beta$ & $P$ & $E$ & $x$ & $k$ & $R$ & $R$ & $E$ & $G$ & I & $\mathrm{T}$ & Ö \\
\hline$L$ & $E$ & $M$ & $A$ & $k$ & I & $S$ & $\ddot{U}$ & $x$ & $E$ & I & $\beta$ \\
\hline$E$ & $y$ & V & $M$ & $E$ & $G$ & $\beta$ & Z & $P$ & $C$ & $C$ & $G$ \\
\hline$x$ & I & W & $L$ & I & $D$ & 0 & $k$ & 0 & $R$ & K & $E$ \\
\hline 4 & A & & & & & & 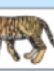 & $7 x$ & & & \\
\hline
\end{tabular}

Figure S7. Exercise "Griddle". Examples: the German word "Elch" for "moose" in the upper left corner (forwards) and the German word "Giraffe" for "giraffe" in the middle of the word grid (vertically backwards).

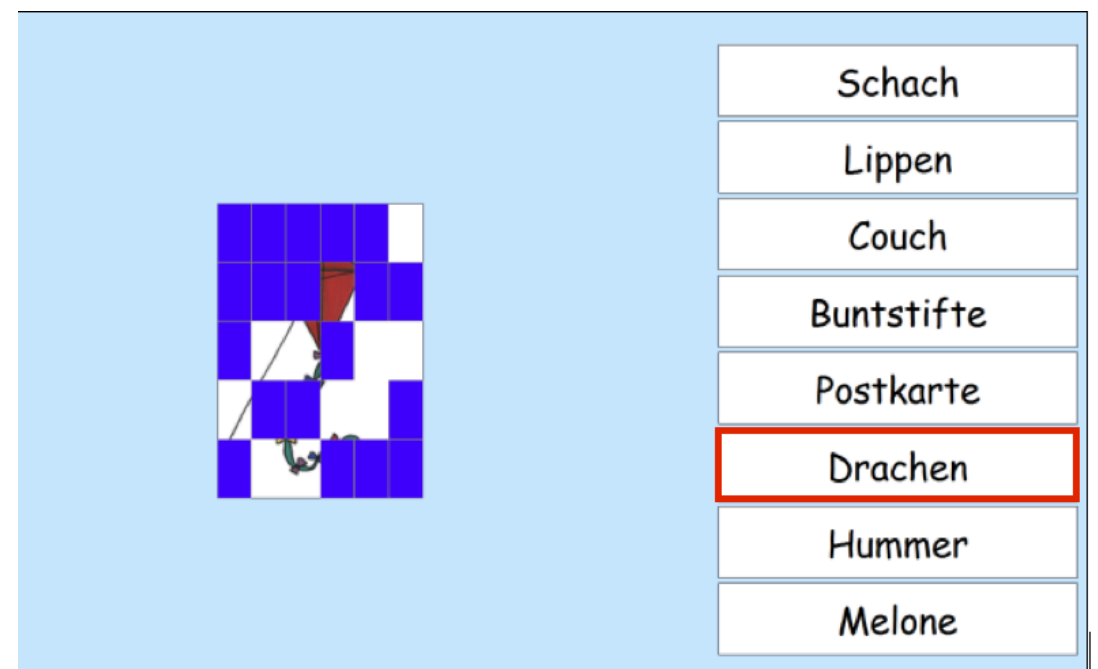

Figure S8. Exercise “Klexsklick". Example "Drachen”, the German word for "kite”. 


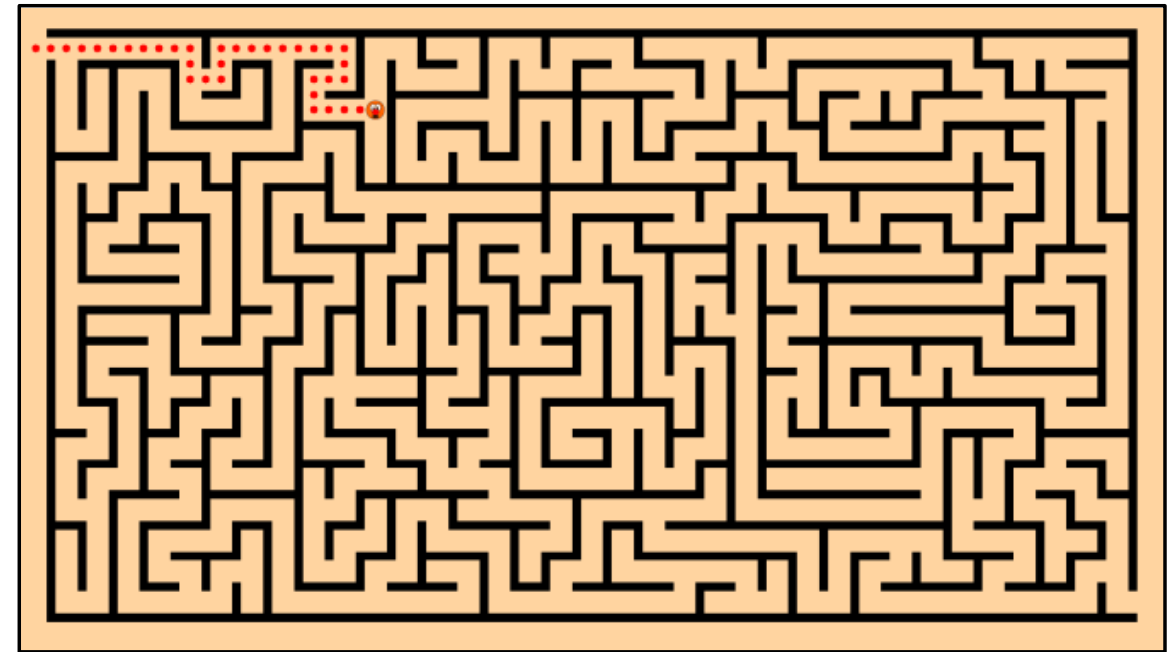

Figure S9. Exercise "Labyrinth".

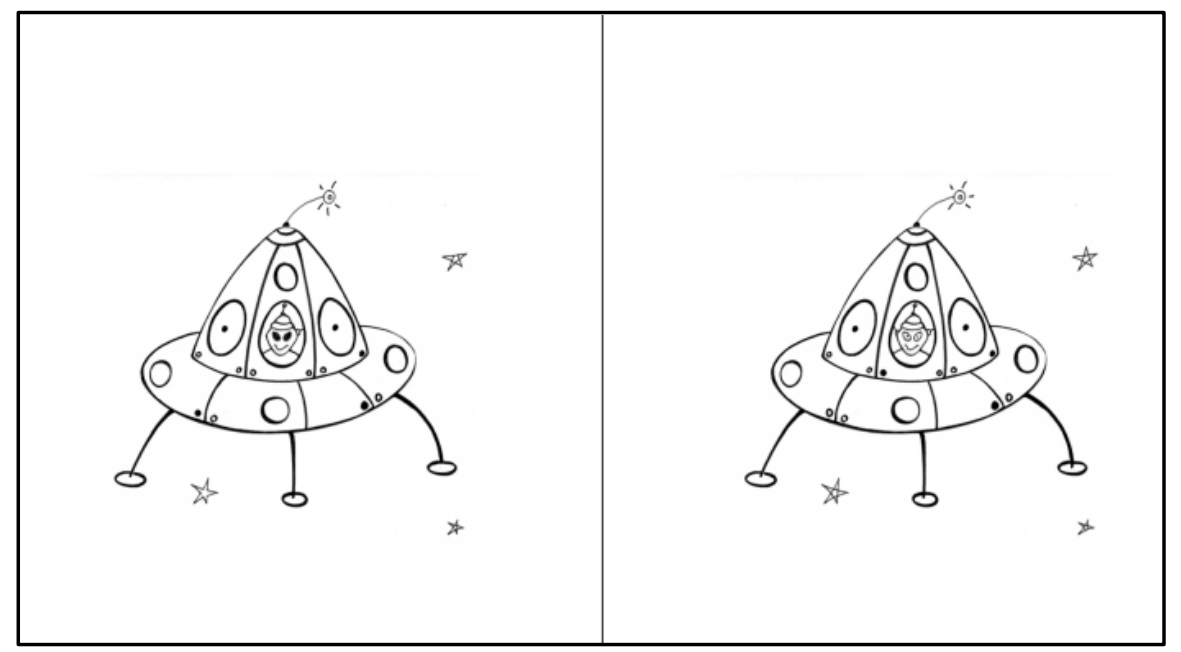

Figure S10. Exercise "Different pictures".

Table S2. Backward multiple regression predicting cognitive improvement in experimental condition.

Improvement in Verbal Memory Subtest VLMT 1 - 5 RCI

$\beta$ (standardized coefficients)

\begin{tabular}{|c|c|c|c|c|c|c|c|}
\hline Predictor & Step 1 & Step 2 & Step 3 & Step 4 & Step 5 & Step 6 & Step 7 \\
\hline $\begin{array}{l}\text { Baseline } \\
\text { Performance }\end{array}$ & -0.302 & -0.291 & -0.333 & -0.317 & $-0.358+$ & $-0.439^{\star}$ & $-0.453^{*}$ \\
\hline $\begin{array}{l}\text { Depression } \\
\text { (BDI-II) }\end{array}$ & -0.183 & -0.189 & -0.192 & -0.171 & $\mathrm{x}$ & $\mathrm{x}$ & $\mathrm{x}$ \\
\hline Grade & -0.423 & $-0.429^{+}$ & $-0.477^{*}$ & $-0.402^{+}$ & $-0.461^{*}$ & $-0.477^{\star}$ & $-0.546^{\star *}$ \\
\hline SCC (SMI-Q) & $-0.494^{+}$ & $-0.498^{+}$ & $-0.426^{+}$ & -0.371 & $-0.434^{*}$ & $-0.321^{+}$ & $-0.291^{+}$ \\
\hline $\begin{array}{l}\text { Technology } \\
\text { Commitment }\end{array}$ & -0.211 & -0.236 & -0.238 & -0.232 & -0.208 & $\mathrm{x}$ & $\mathrm{x}$ \\
\hline Age & 0.155 & 0.144 & $\mathrm{x}$ & $\mathrm{x}$ & $\mathrm{x}$ & $\mathrm{x}$ & $\mathrm{x}$ \\
\hline
\end{tabular}




\section{Continued}

\begin{tabular}{|c|c|c|c|c|c|c|c|c|}
\hline Education & -0.149 & -0.149 & -0.152 & -0.162 & -0.179 & $\mathrm{x}$ & $\mathrm{x}$ & \\
\hline Sex & 0.042 & $\mathrm{x}$ & $\mathrm{x}$ & $\mathrm{x}$ & $\mathrm{x}$ & $\mathrm{x}$ & $\mathrm{x}$ & \\
\hline $\begin{array}{l}\text { Self-efficacy } \\
\quad \text { (SWE) }\end{array}$ & -0.234 & -0.233 & -0.175 & $\mathrm{x}$ & $\mathrm{x}$ & $\mathrm{x}$ & $\mathrm{x}$ & \\
\hline$R_{\text {adj }}^{2}$ & $0.420^{+}$ & $0.466^{*}$ & $0.491^{*}$ & $0.501^{*}$ & $0.511^{* *}$ & $0.514^{* *}$ & $0.510^{*}$ & \\
\hline$n$ & 21 & & & & & & & \\
\hline \multicolumn{9}{|c|}{ Improvement in Verbal Memory Subtest VLMT 7 RCI } \\
\hline & \multicolumn{8}{|c|}{$\beta$ (standardized coefficients) } \\
\hline Predictor & Step 1 & Step 2 & Step 3 & Step 4 & Step 5 & Step 6 & Step 7 & Step 8 \\
\hline $\begin{array}{c}\text { Baseline } \\
\text { Performance }\end{array}$ & $-0.628^{\star}$ & $-0.629^{*}$ & $-0.624^{*}$ & $-0.626^{*}$ & $-0.670^{* *}$ & $-0.682^{\star *}$ & $-0.614^{* *}$ & $-0.595^{\star *}$ \\
\hline $\begin{array}{l}\text { Depression } \\
\text { (BDI-II) }\end{array}$ & 0.254 & 0.255 & 0.254 & 0.250 & 0.242 & 0.240 & 0.136 & $\mathrm{x}$ \\
\hline Grade & -0.475 & -0.474 & -0.465 & $-0.478^{+}$ & $-0.561^{\star}$ & $-0.591^{\star *}$ & $-0.573^{\star *}$ & $-0.513^{\star *}$ \\
\hline SCC (SMI-Q) & -0.214 & -0.211 & -0.212 & -0.240 & -0.185 & -0.189 & $\mathrm{x}$ & $\mathrm{x}$ \\
\hline $\begin{array}{l}\text { Technology } \\
\text { Commitment }\end{array}$ & -0.007 & $\mathrm{x}$ & $\mathrm{x}$ & $\mathrm{x}$ & $\mathrm{x}$ & $\mathrm{x}$ & $\mathrm{x}$ & $\mathrm{x}$ \\
\hline Age & 0.134 & 0.136 & 0.136 & 0.157 & $\mathrm{x}$ & $\mathrm{x}$ & $\mathrm{x}$ & $\mathrm{x}$ \\
\hline Education & 0.019 & 0.019 & $\mathrm{x}$ & $\mathrm{x}$ & $\mathrm{x}$ & $\mathrm{x}$ & $\mathrm{x}$ & $\mathrm{x}$ \\
\hline Sex & 0.140 & 0.142 & 0.142 & 0.151 & 0.130 & $\mathrm{x}$ & $\mathrm{x}$ & $\mathrm{x}$ \\
\hline $\begin{array}{l}\text { Self-efficacy } \\
\quad \text { (SWE) }\end{array}$ & 0.121 & 0.057 & 0.059 & $\mathrm{x}$ & $\mathrm{x}$ & $\mathrm{x}$ & $\mathrm{x}$ & $\mathrm{x}$ \\
\hline$R_{\text {adj }}^{2}$ & 0.183 & 0.251 & $0.308^{+}$ & $0.355^{+}$ & $0.378^{*}$ & $0.397^{\star}$ & $0.406^{* *}$ & $0.422^{* *}$ \\
\hline$n$ & 21 & & & & & & & \\
\hline \multicolumn{9}{|c|}{ Improvement in Figural Memory WMS VR Direct Recall RCI } \\
\hline \multicolumn{9}{|c|}{$\beta$ (standardized coefficients) } \\
\hline Predictor & Step 1 & Step 2 & Step 3 & Step 4 & Step 5 & Step 6 & Step7 & \\
\hline $\begin{array}{c}\text { Baseline } \\
\text { Performance }\end{array}$ & $-0.673^{+}$ & $-0.682 .^{*}$ & $-0.751^{\star *}$ & $-0.781^{\star *}$ & $-0.834^{* *}$ & $-0.761^{\star *}$ & $-0.711^{\star *}$ & \\
\hline $\begin{array}{l}\text { Depression } \\
\text { (BDI-II) }\end{array}$ & -0.184 & -0.187 & -0.131 & $\mathrm{x}$ & $\mathrm{x}$ & $\mathrm{x}$ & $\mathrm{x}$ & \\
\hline Grade & -0.168 & -0.182 & -0.191 & -0.237 & -0.200 & $\mathrm{x}$ & $\mathrm{x}$ & \\
\hline SCC (SMI-Q) & 0.178 & 0.134 & $\mathrm{x}$ & $\mathrm{x}$ & $\mathrm{x}$ & $\mathrm{x}$ & $\mathrm{x}$ & \\
\hline $\begin{array}{c}\text { Technology } \\
\text { Commitment }\end{array}$ & 0.098 & $\mathrm{x}$ & $\mathrm{x}$ & $\mathrm{x}$ & $\mathrm{x}$ & $\mathrm{x}$ & $\mathrm{x}$ & \\
\hline Age & $-0.769^{\star}$ & $-0.801^{\star}$ & $-0.785^{\star}$ & $-0.821^{\star *}$ & $-0.878^{\star *}$ & $-0.783^{\star *}$ & $-0.774^{\star *}$ & \\
\hline Education & 0.180 & 0.186 & 0.161 & 0.155 & $\mathrm{x}$ & $\mathrm{x}$ & $\mathrm{x}$ & \\
\hline Sex & 0.206 & 0.175 & 0.197 & 0.198 & 0.197 & 0.213 & $\mathrm{x}$ & \\
\hline $\begin{array}{l}\text { Self-efficacy } \\
\text { (SWE) }\end{array}$ & 0.222 & 0.226 & 0.162 & 0.202 & 0.217 & 0.300 & $0.355^{+}$ & \\
\hline$R_{\text {adj }}^{2}$ & 0.301 & $0.351^{+}$ & $0.391^{*}$ & $0.417^{\star}$ & $0.431^{*}$ & $0.438^{\star}$ & $0.422^{* *}$ & \\
\hline$n$ & 21 & & & & & & & \\
\hline
\end{tabular}




\section{Continued}

\begin{tabular}{|c|c|c|c|c|c|c|c|}
\hline \multicolumn{8}{|c|}{ Improvement in Figural Memory WMS VR Delayed Recall RCI } \\
\hline \multirow[b]{2}{*}{ Predictor } & \multicolumn{7}{|c|}{$\beta$ (standardized coefficients) } \\
\hline & Step 1 & Step 2 & Step 3 & Step 4 & Step 5 & Step 6 & Step 7 \\
\hline $\begin{array}{c}\text { Baseline } \\
\text { Performance }\end{array}$ & $-0.944^{+}$ & $-0.941^{\star}$ & $-0.916^{\star}$ & $-0.986^{\star *}$ & $-1.002^{\star \star}$ & $-0.919^{\star *}$ & $-0.626^{*}$ \\
\hline Depression (BDI-II) & -0.111 & -0.112 & -0.136 & -0.108 & $\mathrm{x}$ & $\mathrm{x}$ & $\mathrm{x}$ \\
\hline Grade & -0.134 & -0.138 & -0.135 & -0.131 & -0.172 & $\mathrm{x}$ & $\mathrm{x}$ \\
\hline SCC (SMI-Q) & -0.073 & -0.071 & $\mathrm{x}$ & $\mathrm{x}$ & $\mathrm{x}$ & $\mathrm{x}$ & $\mathrm{x}$ \\
\hline $\begin{array}{c}\text { Technology } \\
\text { Commitment }\end{array}$ & $0.537^{+}$ & $0.535^{+}$ & $0.555^{\star}$ & $0.545^{\star}$ & $0.580^{\star}$ & $0.610^{*}$ & $0.623^{*}$ \\
\hline Age & -0.467 & -0.464 & -0.468 & -0.545 & $-0.549^{+}$ & -0.417 & $\mathrm{x}$ \\
\hline Education & -0.010 & $\mathrm{x}$ & $\mathrm{x}$ & $\mathrm{x}$ & $\mathrm{x}$ & $\mathrm{x}$ & $\mathrm{x}$ \\
\hline Sex & $0.498^{+}$ & $0.498^{+}$ & $0.494^{+}$ & 0.491 & $0.509^{*}$ & $0.534^{*}$ & $0.461^{+}$ \\
\hline $\begin{array}{l}\text { Self-efficacy } \\
\quad(S W E)\end{array}$ & -0.115 & -0.117 & -0.102 & $\mathrm{x}$ & $\mathrm{x}$ & $\mathrm{x}$ & $\mathrm{x}$ \\
\hline$R_{\text {adj }}^{2}$ & 0.092 & 0.167 & 0.228 & $0.277^{+}$ & $0.314^{+}$ & $0.334^{*}$ & $0.266^{*}$ \\
\hline$n$ & 21 & & & & & & \\
\hline \multicolumn{8}{|c|}{ Improvement in Brief Test of Attention (BTA) PV } \\
\hline \multicolumn{8}{|c|}{$\beta$ (standardized coefficients) } \\
\hline Predictor & Step 1 & Step 2 & Step 3 & Step 4 & Step 5 & Step 6 & \\
\hline $\begin{array}{c}\text { Baseline } \\
\text { Performance }\end{array}$ & $-0.854^{* * *}$ & $-0.869^{* * \star}$ & $-0.878^{* * *}$ & $-0.566^{* * *}$ & $-0.859^{* * *}$ & $-0.889^{* * *}$ & \\
\hline $\begin{array}{l}\text { Depression } \\
\text { (BDI-II) }\end{array}$ & 0.028 & $\mathrm{x}$ & $\mathrm{x}$ & $\mathrm{x}$ & $\mathrm{x}$ & $\mathrm{x}$ & \\
\hline Grade & -0.041 & -0.030 & $\mathrm{x}$ & $\mathrm{x}$ & $\mathrm{x}$ & $\mathrm{x}$ & \\
\hline SCC (SMI-Q) & $-0.415^{+}$ & $-0.406^{*}$ & $-0.410^{*}$ & $-0.409^{*}$ & $-0.448^{* *}$ & $-0.372^{\star *}$ & \\
\hline $\begin{array}{l}\text { Technology } \\
\text { Commitment }\end{array}$ & -0.178 & -0.175 & -0.169 & -0.167 & -0.161 & $\mathrm{x}$ & \\
\hline Age & -0.307 & $-0.311^{+}$ & $-0.303^{+}$ & $-0.311^{+}$ & $-0.271^{*}$ & $-0.246^{+}$ & \\
\hline Education & 0.057 & 0.060 & 0.053 & $\mathrm{x}$ & $\mathrm{x}$ & $\mathrm{x}$ & \\
\hline Sex & 0.228 & 0.228 & 0.233 & 0.230 & $0.248^{+}$ & $0.293^{*}$ & \\
\hline $\begin{array}{l}\text { Self-efficacy } \\
\quad(\text { SWE) }\end{array}$ & 0.068 & 0.069 & 0.079 & 0.076 & $\mathrm{x}$ & $\mathrm{x}$ & \\
\hline$R_{\text {adj }}^{2}$ & $0.651^{\star *}$ & $0.679^{\star *}$ & $0.703^{* * *}$ & $0.721^{\star * \star}$ & $0.735^{\star * *}$ & $0.735^{\star * *}$ & \\
\hline$n$ & 21 & & & & & & \\
\hline
\end{tabular}




\section{Continued}

Improvement in Speed of Processing TMT-A PV

\begin{tabular}{|c|c|c|c|c|c|c|c|}
\hline \multirow[b]{2}{*}{ Predictor } & \multicolumn{7}{|c|}{$\beta$ (standardized coefficients) } \\
\hline & Step 1 & Step 2 & Step 3 & Step 4 & Step 5 & Step 6 & Step 7 \\
\hline $\begin{array}{c}\text { Baseline } \\
\text { Performance }\end{array}$ & $-0.707^{\star}$ & $-0.720^{\star *}$ & $-0.718^{*}$ & $-0.718^{\star *}$ & $-0.704^{\star *}$ & $-0.639^{\star * *}$ & $-0.720^{\star * *}$ \\
\hline $\begin{array}{l}\text { Depression } \\
\text { (BDI-II) }\end{array}$ & -0.358 & $-0.350^{+}$ & $-0.343^{+}$ & $-0.338^{+}$ & $-0.361^{\star}$ & $-0.372^{\star}$ & $-0.368^{\star}$ \\
\hline Grade & 0.034 & 0.036 & $\mathrm{x}$ & $\mathrm{x}$ & $\mathrm{x}$ & $\mathrm{x}$ & $\mathrm{x}$ \\
\hline SCC (SMI-Q) & 0.035 & $\mathrm{X}$ & $\mathrm{x}$ & $\mathrm{x}$ & $\mathrm{x}$ & $\mathrm{x}$ & $\mathrm{x}$ \\
\hline $\begin{array}{l}\text { Technology } \\
\text { Commitment }\end{array}$ & 0.284 & 0.274 & -0.269 & 0.287 & 0.299 & 0.242 & $0.275^{+}$ \\
\hline Age & 0.117 & 0.134 & 0.123 & 0.136 & 0.154 & $\mathrm{x}$ & $\mathrm{x}$ \\
\hline Education & 0.181 & 0.175 & 0.184 & 0.186 & 0.191 & 0.194 & $\mathrm{x}$ \\
\hline Sex & -0.036 & -0.036 & -0.042 & $\mathrm{x}$ & $\mathrm{x}$ & $\mathrm{x}$ & $\mathrm{x}$ \\
\hline Self-efficacy (SWE) & 0.103 & 0.094 & 0.084 & 0.070 & $\mathrm{x}$ & $\mathrm{x}$ & $\mathrm{x}$ \\
\hline$R_{\text {adj }}^{2}$ & $0.430^{+}$ & $0.477^{*}$ & $0.516^{*}$ & $0.549^{* *}$ & $0.575^{* \star}$ & $0.581^{* * *}$ & $0.570^{* * *}$ \\
\hline \multirow[t]{3}{*}{$n$} & 21 & & & & & & \\
\hline & \multicolumn{7}{|c|}{ Improvement in Set Shifting TMT-B PV } \\
\hline & \multicolumn{7}{|c|}{$\beta$ (standardized coefficients) } \\
\hline Predictor & Step 1 & Step 2 & Step 3 & Step 4 & Step 5 & Step 6 & Step 7 \\
\hline $\begin{array}{c}\text { Baseline } \\
\text { Performance }\end{array}$ & $-0.672^{+}$ & $-0.664^{+}$ & $-0.655^{*}$ & $-0.697^{*}$ & $-0.725^{*}$ & $-0.759^{* *}$ & $-0.466^{\star}$ \\
\hline $\begin{array}{l}\text { Depression } \\
\text { (BDI-II) }\end{array}$ & 0.193 & 0.196 & 0.188 & 0.181 & 0.151 & $\mathrm{x}$ & $\mathrm{x}$ \\
\hline Grade & -0.129 & -0.124 & -0.130 & -0.092 & $\mathrm{x}$ & $\mathrm{x}$ & $\mathrm{x}$ \\
\hline SCC (SMI-Q) & -0.044 & -0.027 & $\mathrm{x}$ & $\mathrm{x}$ & $\mathrm{x}$ & $\mathrm{x}$ & $\mathrm{x}$ \\
\hline $\begin{array}{l}\text { Technology } \\
\text { Commitment }\end{array}$ & $0.529^{+}$ & 0.526 & $0.535^{*}$ & $0.559^{*}$ & $0.580^{* *}$ & 0.525 & $0.400^{*}$ \\
\hline Age & 0.363 & 0.343 & 0.329 & 0.362 & 0.423 & 0.413 & $\mathrm{x}$ \\
\hline Education & 0.083 & 0.083 & 0.087 & $\mathrm{x}$ & $\mathrm{x}$ & $\mathrm{x}$ & $\mathrm{x}$ \\
\hline Sex & -0.341 & -0.346 & $-0.343^{+}$ & $-0.344^{+}$ & $-0.326^{+}$ & $-0.367^{\star}$ & $-0.351^{+}$ \\
\hline $\begin{array}{l}\text { Self-efficacy } \\
\quad \text { (SWE) }\end{array}$ & -0.034 & $\mathrm{X}$ & $\mathrm{x}$ & $\mathrm{x}$ & $\mathrm{x}$ & $\mathrm{x}$ & $\mathrm{x}$ \\
\hline$R_{\text {adj }}^{2}$ & 0.315 & $0.371^{+}$ & $0.419^{\star}$ & $0.452^{\star}$ & $0.482^{*}$ & $0.491^{\star *}$ & $0.444^{\star *}$ \\
\hline$n$ & 21 & & & & & & \\
\hline
\end{tabular}




\section{Continued}

\begin{tabular}{|c|c|c|c|c|c|c|c|}
\hline \multirow[b]{3}{*}{ Predictor } & \multicolumn{7}{|c|}{ Improvement in RWT Verbal Letter Fluency PV } \\
\hline & \multicolumn{7}{|c|}{$\beta$ (standardized coefficients) } \\
\hline & Step 1 & Step 2 & Step 3 & Step 4 & Step 5 & Step 6 & Step 7 \\
\hline $\begin{array}{c}\text { Baseline } \\
\text { Performance }\end{array}$ & -0.409 & -0.409 & $-0.409^{+}$ & $-0.417^{+}$ & $-0.413^{\star}$ & $-0.467^{\star}$ & $-0.467^{\star}$ \\
\hline $\begin{array}{c}\text { Depression } \\
\text { (BDI-II) }\end{array}$ & -0.057 & -0.057 & -0.051 & -0.050 & $\mathrm{x}$ & $\mathrm{x}$ & $\mathrm{x}$ \\
\hline Grade & 0.001 & $\mathrm{X}$ & $\mathrm{x}$ & $\mathrm{x}$ & $\mathrm{x}$ & $\mathrm{x}$ & $\mathrm{x}$ \\
\hline SCC (SMI-Q) & $-0.653^{+}$ & $-0.653^{+}$ & $-0.668^{\star}$ & $-0.662^{*}$ & $-0.681^{*}$ & $-0.668^{*}$ & $-0.546^{*}$ \\
\hline $\begin{array}{l}\text { Technology } \\
\text { Commitment }\end{array}$ & -0.421 & -0.421 & -0.412 & -0.400 & -0.399 & $-0.434^{+}$ & $-0.406^{+}$ \\
\hline Age & -0.033 & -0.033 & $\mathrm{x}$ & $\mathrm{x}$ & $\mathrm{x}$ & $\mathrm{x}$ & $\mathrm{x}$ \\
\hline Education & -0.194 & -0.194 & -0.191 & -0.188 & -0.194 & $\mathrm{x}$ & $\mathrm{x}$ \\
\hline Sex & -0.040 & -0.040 & -0.033 & $\mathrm{x}$ & $\mathrm{x}$ & $\mathrm{x}$ & $\mathrm{x}$ \\
\hline $\begin{array}{l}\text { Self-efficacy } \\
\quad \text { (SWE) }\end{array}$ & -0.254 & -0.254 & -0.271 & -0.277 & -0.264 & -0.238 & $\mathrm{x}$ \\
\hline$R_{\text {adj }}^{2}$ & 0.076 & 0.153 & 0.217 & $0.272^{+}$ & $0.318^{+}$ & $0.319^{*}$ & $0.307^{\star}$ \\
\hline$n$ & 21 & & & & & & \\
\hline
\end{tabular}

Note. BDI-II = Beck's Depression Inventory. $\mathrm{PC}=$ percentage change score. $\mathrm{RCI}=$ reliable change index. $\mathrm{RWT}=$ Regensburger Wortflüssigkeits test. $\mathrm{SCC}=$ Subjective Cognitive Concerns. SMI-Q = Subjective Memory Impairment Questionnaire. SWE = self-efficacy expectation.TMT = Trail Making Test. VLMT = Verbaler Lern- und Merkfähigkeits test. WMS VR = Wechsler Memory Scale (German version) subtest Visual Reproduction. For RWT semantic-alternating fluency only baseline performance was a significant predictor $\left(\beta=-0.476^{*} ; R^{2}=0.186^{*}\right)$. For improvement in visual-spatial functioning (LPS $50+\mathrm{RCI})$ only baseline performance was a significant predictor $\left(\beta=-0.461^{*} ; R^{2}=0.171^{\star}\right)$. For improvement in planning abilities (Key Search PC) no significant predictors were identified. ${ }^{+} \mathrm{p} \leq 0.10 ;{ }^{*} \mathrm{p} \leq 0.05 ;{ }^{* *} \mathrm{p} \leq 0.01 ;{ }^{* *} \mathrm{p} \leq 0.001$. 